\title{
Perceptions of quality across the maternal care continuum in the context of a health financing intervention: Evidence from a mixed methods study in rural Malawi
}

Christabel Kambala1, ${ }^{1,3^{*}}$, Julia Lohmann ${ }^{1}$, Jacob Mazalale ${ }^{1,2}$, Stephan Brenner ${ }^{1}$, Malabika Sarker ${ }^{1,4}$, Adamson S. Muula ${ }^{2}$ and Manuela De Allegri ${ }^{1}$

\begin{abstract}
Background: In 2013, Malawi with its development partners introduced a Results-Based Financing for Maternal and Newborn Health (RBF4MNH) intervention to improve the quality of maternal and newborn health-care services. Financial incentives are awarded to health facilities conditional on their performance and to women for delivering in the health facility. We assessed the effect of the RBF4MNH on quality of care from women's perspectives.

Methods: We used a mixed-method prospective sequential controlled pre- and post-test design. We conducted 3060 structured client exit interviews, 36 in-depth interviews and 29 focus group discussions (FGDs) with women and 24 in-depth interviews with health service providers between 2013 and 2015. We used difference-in-differences regression models to measure the effect of the RBF4MNH on experiences and perceived quality of care. We used qualitative data to explore the matter more in depth.

Results: We did not observe a statistically significant effect of the intervention on women's perceptions of technical care, quality of amenities and interpersonal relations. However, in the qualitative interviews, most women reported improved health service provision as a result of the intervention. RBF4MNH increased the proportion of women reporting to have received medications/treatment during childbirth. Participants in interviews expressed that drugs, equipment and supplies were readily available due to the RBF4MNH. However, women also reported instances of neglect, disrespect and verbal abuse during the process of care. Providers attributed these negative instances to an increased workload resulting from an increased number of women seeking services at RBF4MNH facilities.

Conclusion: Our qualitative findings suggest improvements in the availability of drugs and supplies due to RBF4MNH. Despite the intervention, challenges in the provision of quality care persisted, especially with regard to interpersonal relations. RBF interventions may need to consider including indicators that specifically target the provision of respectful maternity care as a means to foster providers' positive attitudes towards women in labour. In parallel, governments should consider enhancing staff and infrastructural capacity before implementing RBF.
\end{abstract}

Keywords: Results-Based Financing, Malawi, Quality of care, Demand-side financing, Performance-based financing, Maternal care, Conditional Cash Transfers

\footnotetext{
* Correspondence: christabel_kambala@yahoo.com; ckambala@poly.ac.mw

${ }^{1}$ Institute of Public Health, Faculty of Medicine, Heidelberg University, Im

Neuenheimer Feld 324, D-69120 Heidelberg, Germany

${ }^{2}$ School of Public Health and Family Medicine, College of Medicine,

University of Malawi, Private Bag 360, Chichiri, Blantyre 3, Malawi

Full list of author information is available at the end of the article
} 


\section{Background}

Poor quality of maternal healthcare services has been recognised as the major factor contributing to maternal and newborn deaths in most low and middle income countries (LMICs) [1]. Insufficient human resources [2,3], poor training of health staff [2], inadequate infrastructures, and shortages in equipment and medications have been identified as the main causes of structural inadequacies contributing to poor health service delivery [3, 4]. In turn, it has been argued that these inadequacies are largely the product of both insufficient and inefficient health financing structures [5]. Specifically, it has been postulated that input-based financing coupled with excessive centralization exacerbates the constraints already imposed by scarcity of resources and ends up depriving healthcare workers of the autonomy needed to make decisions that are conducive to the delivery of quality health services in these settings [6].

Performance Based Financing (PBF) has been advanced as a health system intervention able to improve healthcare service delivery in LMICs [7]. Specifically, PBF is expected to produce changes in quantity and quality of service delivery by promoting a shift from input-based to output-based financing $[7,8]$. Under PBF, health-care providers, health facilities, and district health management teams enter in a contractual arrangement with a purchasing agent (either the government or a development partner) and are financially rewarded only upon reaching predefined performance targets related to the quantity and quality of the healthcare services provided [7-9]. Under PBF, both quantity and quality outputs are verified on a regular basis [7]. The shift from input-based to output-based financing is further coupled with increased autonomy, allowing healthcare providers to make independent choices about resource allocation at the level of their facilities [10,11].

Based on principal-agent theory, it is expected that linking payments to specific quantity and quality outputs can more easily re-align healthcare workers' behaviour towards the provision of quality services than inputbased financing ever did [13, 14]. In addition, increased autonomy is expected to empower healthcare providers to overcome health system barriers that are not conducive to quality health service delivery by allowing them to make independent decisions about the investments that can best benefit the facility they work at and the community they serve $[10,11]$. Last, but surely not least, verification is expected to make healthcare providers more accountable both towards the communities and the government they work for, in countries where healthcare employees have traditionally lacked accountability $[7,12]$.

Over the last decade, several LMIC governments have adopted PBF, either alone or in combination with demand-side financing interventions, such as Conditional Cash Transfers (CCT) [7, 10, 13-18]. CCT are financial incentives acting on the demand-side to motivate consumption of specific healthcare services. While PBF acts on the supply-side by rewarding provision of a given service at a set quality standard, CCT act on the demand-side by rewarding consumption of a given service $[7,9]$. When used in combination, PBF and CCT are expected to produce changes on both supply and demand, resulting in increases both in the quantity and the quality of the services delivered [7]. There have been concerns raised against the provision of CCT. If demand for a given service be increased beyond the current health system capacity, it will potentially counteract the positive effect on quality of service delivery promoted by PBF [19].

With specific reference to maternal care services, which represent the focus of our investigation in this paper, PBF has been shown to improve use and quality of maternal and child health services in Burundi [20]; and to improve utilization, coverage and emergency referrals with enhanced quality of provider performance in Haiti [21]. PBF has also been shown to increase rates of assisted births, antenatal care utilization and uptake of modern family planning in Burundi [22]; to increase utilization and coverage of maternal services in India, Kenya and Uganda [14]; and to increase the number of institutional deliveries in Rwanda [13]. Further, PBF has been shown to improve structural quality such as an increase in the availability of staff in Democratic Republic of Congo [10]; and to improve process quality such as history taking, examination of pregnant women, testing blood and urine during ANC in Egypt [23] to name a few.

Additional evidence, however, has indicated that the provision of financial incentives depending on performance is not always sufficient to improve the quality of the care provided $[6,24]$ and may result in negative outcomes on structural quality, such as a decrease in the level of availability of equipment and drugs [25], may lead to neglect of untargeted services [6, 24], provision of needless or detrimental services and fraud [24, 26]. On the demand side, CCT linked to provision of maternity services are treated with caution, albeit the absence of concrete evidence, due to the fear that they may encourage women to have additional children and to decrease access to unrewarded interventions [6].

The review presented above clearly indicates that knowledge on the effects of PBF on quality of service delivery is still limited. In addition, the studies reviewed focused exclusively on a quantitative assessment of structural and process dimensions [25] measured at the health facility level. Little attention has so far been paid to understanding if and how the experiential dimension 
of quality, that is to say the quality of service delivery as experienced directly by consumers, changes as a function of the introduction of PBF in a given setting. Since quality of care is widely recognized to be a multidimensional $[1,27]$ construct, the exploration of experiential dimensions deserves the same attention as the exploration of structural and process elements [28]. Specifically, according to Wilde et al. (1993), 'clients' perceptions of good quality care are formed by the intersection between resources available to the health service organisation and the patient preferences considered from four dimensions: the medical-technical competence of the caregivers, the physical-technical conditions of the care organization, the identityorientation in the attitudes and actions of the caregivers, and the socio-cultural atmosphere of the care "[29]. Thus, a full understanding of the effect of PBF on quality of care cannot be limited to quantitative assessment of structural and process elements, but needs to account for an analysis of these experiential elements as well. Further, little is known on the effect of incentives in relation to women's experiences and perceptions of quality of care on technical care, quality of amenities and interpersonal relations.

Our mixed-methods study aimed to fill this gap in knowledge, by assessing the effect of an intervention combining PBF and CCT on women's experiences and perceptions of the quality of maternal and neonatal care services delivered in rural Malawi.

\section{Study setting}

This study was conducted in Malawi where a Result Based Financing Initiative (combining PBF and CCT) (described below) is being implemented as a strategy to improve the utilization and the quality of maternal and newborn healthcare services. Malawi is a low income country in sub-Saharan Africa (SSA) and is located to the south of the equator [30]. The country is divided into three regions: the Northern, Central and Southern regions. Each region is divided into districts and there are 28 in total [31]. Estimates in 2015 indicated that the population of Malawi was at 17,261,736 million [32].

Malawi is among the countries with highest maternal and neonatal mortalities worldwide with a Maternal Mortality Ratio (MMR) of 574/100, 000 live births and a Neonatal Mortality Rate (NMR) of 29/1000 live births as estimated in 2015 [31]. A weak health system and poor quality of care are recognized as the main factors contributing to continuing high rates of maternal and neonatal deaths [33]. Poor quality of care is mostly attributed to an inequitable distribution of health facilities, poor functioning of the referral system, poor structural amenities, often non-functional equipment, poor or no supply of drugs and other essential supplies, as well as few skilled birth attendants [33-35]. Compounding the problem are factors that hinder access to maternal health services, such as long distances to health facilities and lack of finances for transportation [35-38]. Other hindrances include lack of finances for purchasing delivery related items (i.e. women may fear to go to the health facility without satisfying the requirements for an expectant mother to bring delivery related items e.g. wrappers for the baby, a basin for bathing the baby and a plastic sheet to be used in place of a Mackintosh roll [waterproof sheet] on the delivery bed) and upkeep while in the facility [35-38]. Furthermore, the literature consistently indicates poor provider-patient interactions, whereby women report rude and disrespectful treatment during child-birth [36, 37]. In spite of all these hindrances, $96 \%$ of women receive antenatal care (ANC) at a health facility at least once, $45 \%$ use ANC services at least four times, 90\% deliver in a health facility and $81 \%$ receive postnatal care (PNC) within 2 days of delivery [31].

\section{Results Based Financing for Maternal and Newborn Health (RBF4MNH) Initiative in Malawi}

In 2013, the Ministry of Health $(\mathrm{MoH})$ of Malawi adopted the Results-Based Financing for Maternal and Newborn Health (RBF4MNH) Initiative. The aim of the Initiative is to improve the quality of maternal and newborn care services while maintaining high service utilization in both public and selected private not-forprofit facilities. The $\mathrm{MoH}$ implements the Initiative through its Reproductive Health Unit (RHU), with funding from the Norwegian and German governments and with technical support from Options Consultancy Services Limited $[39,40]$. The RBF4MNH Initiative is being implemented in 4 (i.e. Balaka, Dedza, Ntcheu and Mchinji) out of 28 districts in Malawi. The four districts together account for about $13.26 \%$ (2000000) of the population of Malawi [31]. Before the launch of the Initiative, the $\mathrm{MoH}$ conducted a feasibility assessment and identified all facilities able to perform all required emergency obstetric and neonatal care (EmONC) signal functions (essential medical interventions for handling complications in the labour ward). Based on this assessment and on geographical location, in 2013, the $\mathrm{MoH}$ selected 18 facilities, where to roll out the intervention and 1 year later (i.e. in 2014) added 10 more facilities. Alongside Basic EmOC facilities, all four public (one per district) and one private not for profit Comprehensive EmOC facilities have been included in the intervention already since 2013 [40].

The RBF4MNH Initiative includes both supply (provision of obstetric services) and demand side (utilization of obstetric services) incentives. The supply side intervention (PBF) comprises financial rewards that 
are provided to health facilities upon attainment of a predefined set of indicators pertaining to clinical and organizational performance during labour, delivery, and newborn care [39]. For example, besides many indicators on clinical performance (e.g. use of partographs during childbirth), quality assurance (e.g. record audits) and service management (e.g. equipment maintenance), RBF4MNH facilities conduct patient satisfaction surveys (exit interviews) on a monthly basis with at least 10 women. Independent staff (other than those providing care) in the facilities asks women about their satisfaction with services and provider attitudes. Then, providers choose one issue highlighted by patients in the survey and devise an action plan to mitigate the raised concern. During verification of other indicators on clinical and organizational performance, verifiers also check if health facilities have conducted surveys on client satisfaction. If facilities do not have documentation to prove that they have spoken (surveyed) to at least 10 women, this is documented during verification activities and facility rewards are negatively affected. Of the total financial rewards received on a quarterly basis, $30 \%$ are to be invested into the health facility; the remaining $70 \%$ can be paid out to staff as bonuses. At intervention facilities, initial investments were made into facilities' infrastructure and equipment to ensure minimum standards for provision of quality maternal and neonatal health-care services before the intervention was rolled out [39]. Further to this, healthcare providers in intervention facilities were trained (refresher courses) in antenatal management, obstetric care and quality assurance. In addition to the incentives being directed towards the single facilities, District Health Management Teams are also rewarded based on the overall performance of a district, including both RBF4MNH and non-RBF4MNH facilities. This set of incentives is meant to ensure that that management teams continue to perform adequate supervision across all facilities and do not re-direct resources exclusively towards intervention facilities.

The demand side intervention comprises conditional cash transfers (CCT) to women who deliver in a health facility. A fixed lump sum is provided to recover upfront costs of delivery-related items (e.g. wrappers for the baby) and food while staying at the facility for $48 \mathrm{~h}$ after delivery. In addition, a variable sum is reimbursed for transport depending on distance travelled [39]. Receipt of the CCT is conditional upon having already registered at the facility during antenatal care, with Health Surveillance Assistants verifying women's eligibility by checking on their actual village of residence.

In line with the overall theory of change of PBF described in the introduction, the RBF4MNH Initiative aims at increasing utilization of obstetric services (facility-based delivery and 48 -h stay post-partum) through the application of CCT and quality of service delivery through the application of PBF with incentives being closely tied to specific quality targets (the list is attached as an appendix).

\section{Methods \\ Study design}

Our study was conducted within the framework of a larger evaluation set to assess the impact of the RBF4MNH Initiative (including all of its elements, PBF and CCT) on a wide range of indicators related to utilization and quality of maternal and newborn care [39]. The evaluation relied on a mixed-methods prospective sequential controlled pre- and post-test design with independent controls, whereby we integrated quantitative and qualitative methods of data collection and analysis within a single design [39]. The choice of study design was determined in light of the fact that the intervention facilities were purposely (and not randomly) selected by the $\mathrm{MoH}$ among the complete set of EmOC facilities in the four concerned districts. As controls, we used the EmOC facilities sampled during the $\mathrm{MoH}$ baseline feasibility assessment, but later not included in the intervention. This ensured comparability between intervention and control facilities, since the two shared a set of basic characteristics linked to their capacity to perform EmOC functions. The 2014 expansion of the RBF4MNH Initiative described earlier, however, meant that our count across intervention and control facilities changed over time. At the onset of the project, we had 18 intervention and 15 control facilities, while at endterm we counted 23 intervention and 10 control facilities. Thus, 1 year into our study (after midterm data collection), five facilities initially included as controls switched to the intervention group due to a natural scale up of the intervention.

We collected data prospectively following the intervention rollout over a 3-year period: at baseline (before the intervention began), at mid-term (a year into the implementation of the intervention), and at end-term (2 years into the implementation of the intervention). We collected quantitative data at all three time-points, while, in line with our sequential design [41], we collected qualitative data only at mid-term and end-term. Although the intervention specifically targeted labour and delivery services, our evaluation efforts addressed the complete range of services along the maternal care continuum. Our approach was justified by a wish to account for both the expected and unexpected effects of the Initiative on pregnant and labouring women and their babies.

With specific reference to the study component described in this manuscript, quantitative data were used to quantify changes in women's experiences and 
perceptions over time, while qualitative data were used to explore experiences and perceptions in greater depth, providing a better understanding and contextualization of the emerging quantitative findings [42]. Both our quantitative and qualitative tools were used to measure perceived quality of care in relation to three dimensions (technical care, quality of amenities and interpersonal relations) identified as essential components of perceived quality of care (QoC) in the literature [29], as already highlighted in the introduction.

\section{Quantitative instrument, data collection strategy, and sample}

In line with the overall design of the impact evaluation [39], we collected quantitative data at three time-points by means of a repeated cross-sectional survey conducted in 2013 (baseline), 2014 (mid-term), and 2015 (endterm) among women exiting maternal and neonatal care services at all 33 health facilities included in the study.

Due to feasibility concerns, we relied on convenience sampling techniques to recruit women for the exit interviews. Each year, over the designated data collection period, we stationed at each facility included in the study for 3 to 5 days and during these days, we approached women exiting ANC, labour and delivery (L\&D), and PNC on a continuous basis. We explained the aim of our study and interviewed all women who agreed to take part in it. To ensure sufficient analytical power, we aimed at interviewing at least eight women for each set of services (ANC, L\&D, and PNC) at each concerned facility and in each survey round (i.e. baseline, mid-term and end-line). This yielded a total sample of 3068 (1407 for ANC; 766 for L\&D; and 895 for PNC). Of the total sample, 2041 women were interviewed at intervention and 1027 at control facilities with an approximately equal number of interviews per data collection round.

We used structured close-ended questionnaires that only differed in some details depending on the service cohort surveyed (i.e. ANC, L\&D, PNC) to collect information on demographic and socio-economic characteristics of the participants, women's experiences with receiving maternal care at the facility (i.e. recall of which services they received during their visit to the facility), and their perceptions of the quality of care they received. Interviews were administered face-to-face by trained enumerators using digital data collection devices under the direct supervision of the authors.

\section{Quantitative outcome variables}

We estimated the impact of RBF4MNH on two sets of outcome variables: women's experiences of maternal care services received during their facility visits; and women's perceptions of the quality of these services.
The first set of outcomes variables, women's experience with maternal care, pertains to women's recall of the exact services they received during the providerpatient encounter that had concluded just prior to our interview. We measured women's experience with care by asking whether they had or had not a number of routine elements in the service delivery process central to technical and interpersonal service quality of ANC, L\&D, PNC: health worker introduction, having been examined, getting an explanation for the examination, having diagnostic tests, getting an explanation for the diagnostic tests, having a blood pressure check, requested consent before procedures, having received medications/treatment, getting an explanation for medication purpose, encouraged to ask questions, offered to have a guardian during delivery and, privacy/ confidentiality protection. Variables were coded as (1) if the woman indicated to have received or experienced a certain treatment and $(0)$ if not (Table 1 ).

The second set of outcome variables pertains to women's perceptions of the quality of the services they

Table 1 Variables on women's experiences with receiving care and their measurement

\begin{tabular}{ll}
\hline Indicator & Measurement \\
\hline Health worker introduction & $0=$ Not done \\
& $1=$ Done \\
& $0=$ Not done \\
& $1=$ Done \\
Examinations/clinical procedures conducted & $0=$ Not explained \\
& $1=$ Explained \\
Explanation of examination/clinical procedures & $0=$ Not administered \\
Medications administered & $1=$ Administered \\
& $0=$ Not explained \\
Explanation of dosage and purpose & $1=$ Explained \\
of medication & $0=$ Not collected \\
Blood specimen collected & $1=$ Collected \\
& $0=$ Not explained \\
Explanation of the purpose of the blood & $1=$ Explained \\
specimen collected & $0=$ Not sought \\
Consent sought before procedures & $1=$ Not sought \\
& $0=$ Not encouraged \\
Encouraged to ask questions & $1=$ Encouraged \\
Blood pressure taken after delivery & $0=$ Not encouraged \\
Encouraged to have a guardian & $1=$ Encouraged \\
Brivacy and confidentiality protected & $0=$ Not protected \\
& $1=$ Protected \\
Blood pressure taken during ANC or PNC & $0=$ Not taken \\
& $1=$ Taken \\
& $0=$ Not taken \\
& $1=$ Taken \\
& $0=$ Not taken \\
& $1=$ Taken \\
& $0=$ Not checked \\
& $1=$ Checked \\
\hline & \\
&
\end{tabular}


received during the provider-patient encounter that had concluded just prior to our interview. In line with our conceptual model which reflects the theoretical postulations on quality outlined by Wilde et al. (1993) [29] to which we refer earlier in the manuscript, we looked at perceived quality on three dimensions for all three services: technical care (i.e. technical aspects of maternal care), quality of amenities, and interpersonal relations. Quality perceptions included the above service elements for which we inquired women's experiences, but went beyond. Perceived quality was measured with psychometric 10-point Likert scales that encompassed a series of brief statements. We developed three parallel, yet distinct surveys (and scales), each addressing the abovementioned dimensions of quality of care with reference to the specific services delivered during ANC, L\&D, and PNC services. The scales for ANC and PNC each encompassed 27 parallel statements, for example, 'The health worker listened to me, 'She/he behaved in a gentle manner,' 'The room was clean and hygienic'. For L\&D, we added four statements to those used for ANC and PNC to capture additional service aspects, for example, "The health worker explained the process of labour and delivery", "The health worker was attentive towards my baby". For each respondent, a score was then calculated as the un-weighted mean of a woman's responses to the statements pertaining to the three quality dimensions, respectively [43]. A detailed description of the measurement and calculation of the QoC scores is provided elsewhere [43]. In the analyses, perceived QoC scores are treated as continuous variables. The full list of statements is provided in Table 2 and questionnaires are attached.

\section{Statistical analysis}

We estimated the effect of PBF on perceived QoC scores and women's experiences using a difference-in-differences (DID) regression model. We relied on two different models: the first model estimated changes from baseline (2013) to mid-term (2014), while the second model estimated changes from baseline to end-term (2015). The purpose of doing so was to differentiate the short-term effect of the intervention ( 1 year into its implementation) from its longer-term effect (2 years into its implementation).

As the DID model used in our analysis is based on linear regression, corresponding standard errors were estimated by Ordinary Least Squares (OLS):

$$
Y_{i t}=\beta_{0}+\beta_{1} T_{i t}+\beta_{2} A_{i}+\beta_{3} T_{i} A_{i}+\varepsilon_{i t},
$$

Where $Y_{i t}=$ outcome variable (i.e. QoC and women's experience); $\mathrm{T}_{\mathrm{it}}=1$ if observation $\mathrm{i}$ occurred in treated facilities and 0 otherwise; $A_{i}=1$ for follow-up time points (mid-term, end-term) after treatment occurred and 0 otherwise and; $\mathrm{T}_{\mathrm{i}} \mathrm{A}_{\mathrm{i}}=$ interaction between treatment and time points.

We adjusted both DID regression models to control for women's age, literacy, socio-economic status (SES; asset index), number of previous pregnancies (gravidity), and a variable that identified the facilities which transitioned from comparison to intervention shortly following our mid-term data collection. The selection of these control variables was informed by previous analyses exploring heterogeneity in our outcome variables [43], to include variables that could potentially mediate the effect of the intervention. Since we observed outcomes at individual level while the intervention was implemented at group level (i.e. health facility), we controlled for clustering at health facility level using the cluster option in Stata [44]. Further, to counteract possible weaknesses in the estimation models due to the limited number of clusters (33), we applied a bootstrapping technique [44-47]. We analysed the data using Stata IC version 13 (StataCorp LP, Texas).

\section{Qualitative procedures}

In line with the overall study design, we collected qualitative data in 2014 (mid-term) and 2015 (end-term). Our qualitative data collection procedures relied on an emergent design, with somewhat different decisions taken at mid-term and at end-term, in light of the emerging quantitative findings. At mid-term, we purposely targeted both intervention $(n=8)$ and control $(n=4)$ facilities, while at end-term, we exclusively targeted intervention facilities $(n=12)$. This difference in sampling choices is due to the fact that while at mid-term, we wished to explore differences between control and intervention areas in relation to the experiential dimension of care, at end-term, we were more interested in exploring the heterogeneity of experiences in relation to the implementation of the RBF4MNH Initiative. Both at mid-term and at end-term, we selected facilities based on how the women included in our quantitative sample had judged their performance, sampling facilities whose quality of service delivery had been rated as either high $(\geq 6 / 10)$ or low $(<6 / 10)$. The application of this purposeful criterion was made possible by the sequential nature of our design, with qualitative data collection being informed by emerging quantitative findings.

At mid-term, we conducted both in-depth exit interviews (IDI) with women exiting ANC, L\&D and PNC services and Focus Group Discussions (FGD) with larger groups of women in communities directly served by the selected facilities. Women selected for FGD included only those who had accessed maternal care services at the selected facilities during the RBF4MNH 
Table 2 Variables used for composite scores for each perception aspect of care adapted to each service cohort

\begin{tabular}{|c|c|}
\hline \multicolumn{2}{|c|}{ Quality of care dimensions measured on a scale of 1-10 ( 1 = complete disagreement; $10=$ complete agreement) } \\
\hline \multirow[t]{10}{*}{ Perception of technical care aspects of received care } & I felt confident in the health worker's ability to assist me \\
\hline & The health workers were competent \\
\hline & She/he was available for me \\
\hline & The midwife/birth attendant or health worker was attentive towards my baby \\
\hline & She/he was supportive with regard to breastfeeding \\
\hline & She/he looked after my pain(s) \\
\hline & She/he made sure me and my baby are well \\
\hline & She/he was with me during labor and delivery \\
\hline & The health workers were well coordinated \\
\hline & The health workers were efficient \\
\hline \multirow[t]{8}{*}{ Perceptions of quality of amenities } & Finding the way to the ANC/del/PNC examination room was easy \\
\hline & The ANC/del/PNC examination room was well equipped \\
\hline & I was set up comfortably in the ANC/del/PNC examination room \\
\hline & The ANC/del/PNC examination room was clean and of satisfactory hygiene \\
\hline & The ANC/del/PNC room was big enough \\
\hline & The ANC/del/PNC examination room was calm, without noise \\
\hline & The ANC/del/PNC examination room was not too dark \\
\hline & The temperature in the delivery room was satisfactory \\
\hline \multirow[t]{13}{*}{ Perception of interpersonal aspects of received care } & The health worker made a good impression on me \\
\hline & She/he listened to me \\
\hline & She/he was attentive towards my needs \\
\hline & She/he behaved in a gentle manner \\
\hline & She/he spoke in a gentle manner \\
\hline & Overall, the health workers had respect \\
\hline & Overall, the health workers were sensitive \\
\hline & Overall, the health workers were nice to me \\
\hline & Overall, the health workers were patient \\
\hline & I believe that people working in this health facility are honest \\
\hline & She/he explained the process of labor and delivery \\
\hline & She/he reassured me concerning my worries \\
\hline & She/he talked in a way that helped me understand my condition \\
\hline
\end{tabular}

implementation period. Since during the mid-term data collection round, we observed greater willingness to talk about experiences of care in a collective (i.e. FGD) rather than in an individual setting (i.e. IDI), at endterm we maintained only the FGD as means of data collection. In addition, for triangulation purposes, we interviewed one maternity health-care provider at each of the selected facilities (Fig. 1 indicates total samples). Data collection was continued until saturation and redundancy were reached. While the number of facilities was sampled in advance, we did not determine the number of interviews and FGD in advance to ensure that we could reach saturation.
The interview guides for both the IDI and the FGD were largely developed to reflect the three dimensions of care (technical care, quality of amenities and interpersonal relations) measured also by our quantitative tool. Trained qualitative interviewers conducted the interviews and led the FGDs in Chichewa (the local language) under the supervision of the corresponding author. All interviews and discussions were audio-recorded, transcribed verbatim, and translated into English before analysis.

\section{Qualitative data analysis}

We analysed data using content analysis which relied on a directed approach to coding [48]. First, we developed 


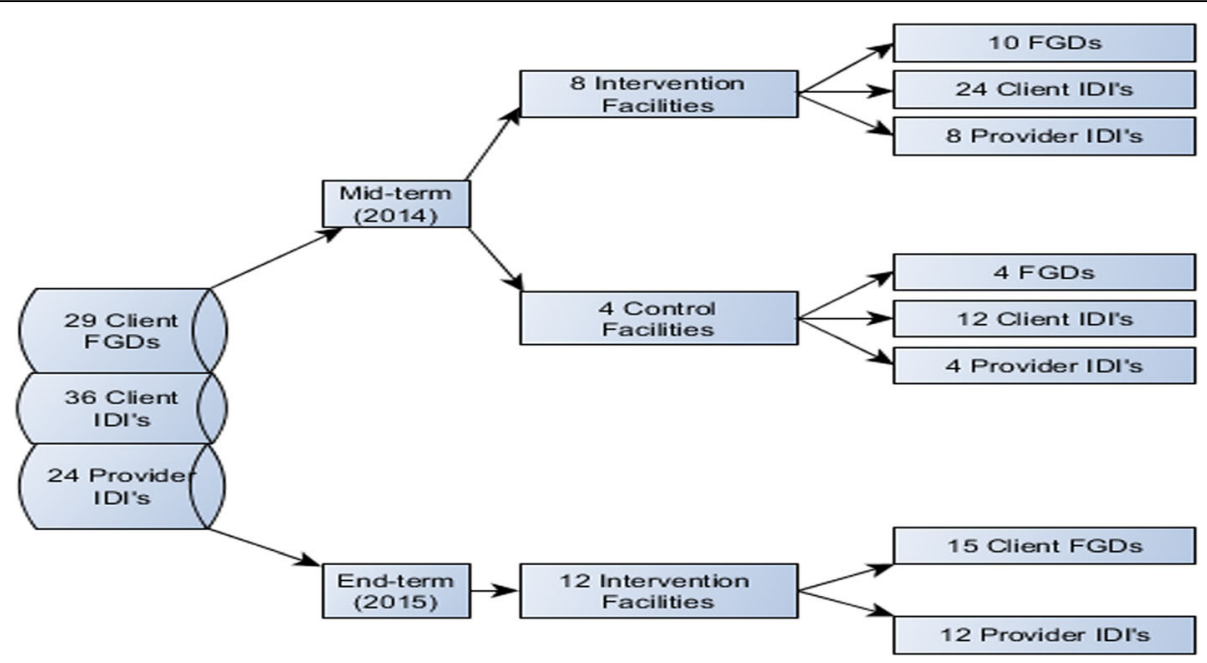

Fig. 1 Qualitative Sampling Design

an initial set of codes based on the conceptual understanding of quality described earlier and on specific elements emerging from a preliminary analysis of the quantitative findings. Second, we let additional codes emerge as we identified new relevant themes while we proceeded through the reading. Third, we grouped similarly coded portions of text according to emerging over-arching themes. Last, we looked for connections and inter-relations across themes to eventually construct a comprehensive narrative [49]. Three analysts coded the material independently and later discussed findings to reach a common interpretation of the material (analysts' triangulation). Any discrepancy identified was resolved by returning to the transcribed material for additional analysis. Analysis was carried out with support of QSR NVivo [50].

The final interpretation of the data emerged in discussion with the broader research team to appraise findings in the light of the results of the wider impact evaluation.

\section{Results}

\section{Quantitative findings}

Characteristics of women attending $L \& D, A N C$ and PNC care

Table 3 reports results, by differentiating them across the three sets of respondents (ANC, L\&D, and PNC) and across intervention and control facilities. In the absence of randomization, this comparison was needed to ensure comparability between women interviewed at intervention and at control facilities, before we proceeded with the DID regression model. Across intervention and controls, women's age in the L\&D sample was 24.0 years (SD: 5.6 ), in the ANC sample was 24.7 years (SD: 5.9) and in the PNC sample was 24.2 years (SD: 5.6 ). Overall, close to $96 \%$ of women were married and close to $65 \%$ of women reported being literate. We observed no significant differences in women's gravidity between the intervention and controls for the L\&D sample and for the ANC sample, with most women reporting having had two pregnancies. Only among PNC respondents, women at comparison facilities reported a higher number of prior pregnancies (3.1, SD: 2.0) than women at intervention facilities (2.6, SD: 2.0).

Effect of RBF4MNH on women's experiences with receiving care during labour and delivery As displayed in Table 4, we observed no statistically significant change attributable to the RBF4MNH on the vast majority of experience indicators reported by women, the exception being a positive effect at end-term on the probability of receiving medication/treatment $(p=0.03)$ and a negative effect at mid-term on the probability of undergoing a blood test $(p=0.03)$.

Effect of RBF4MNH on women's experiences with receiving care during ANC As shown in Table 5, we observed no statistically significant change attributable to the RBF4MNH on many of the experience indicators, except for a positive effect at mid-term on the probability of being offered to keep a guardian during ANC consultation $(p=0.04)$ and a negative effect on the probability of receiving a blood pressure check $(p=0.01)$.

Effect of RBF4MNH on women's experiences with receiving care during PNC We observed no statistically significant change attributable to the RBF4MNH on indicators related to clients' experience with PNC (Table 6). 
Table 3 Sample characteristics of women exiting L\&D, ANC and PNC services

\begin{tabular}{|c|c|c|c|c|c|c|c|c|c|c|c|c|c|c|}
\hline \multirow[t]{3}{*}{ Characteristic } & \multicolumn{4}{|c|}{ Baseline } & \multicolumn{4}{|c|}{ Midterm } & \multicolumn{4}{|c|}{ Endline } & \multirow{2}{*}{\multicolumn{2}{|c|}{$T$-test }} \\
\hline & \multirow{2}{*}{\multicolumn{2}{|c|}{$\frac{\text { Comparison }}{n=067}$}} & \multirow{2}{*}{\multicolumn{2}{|c|}{$\frac{\text { Intervention }}{n=136}$}} & \multirow{2}{*}{\multicolumn{2}{|c|}{$\frac{\text { Comparison }}{n=109}$}} & \multirow{2}{*}{\multicolumn{2}{|c|}{$\frac{\text { Intervention }}{n=224}$}} & \multirow{2}{*}{\multicolumn{2}{|c|}{$\frac{\text { Comparison }}{n=040}$}} & \multirow{2}{*}{\multicolumn{2}{|c|}{$\frac{\text { Intervention }}{n=190}$}} & & \\
\hline & & & & & & & & & & & & & $t$ & Sig \\
\hline \multicolumn{15}{|l|}{ Women exiting L\&D services } \\
\hline Average age in years (mean/SD) & 25.1 & 6.0 & 24.3 & 6.0 & 24.1 & 4.7 & 24.0 & 5.5 & 22.6 & 4.3 & 23.9 & 5.9 & 0.3 & 0.79 \\
\hline Proportion of married women (N/\%) & 61 & 91.0 & 128 & 94.1 & 103 & 94.5 & 218 & 97.3 & 39 & 97.5 & 188 & 99.0 & -2.0 & 0.04 \\
\hline Proportion of literate women (N/\%) & 51 & 76.1 & 83 & 61.0 & 73 & 67.0 & 140 & 62.5 & 24 & 60.0 & 123 & 64.7 & 1.5 & 0.14 \\
\hline Average number of pregnancies (mean/SD) & 3.1 & 1.7 & 2.6 & 1.8 & 2.2 & 1.8 & 2.5 & 2.0 & 1.8 & 2.0 & 2.2 & 2.1 & 0.0 & 0.97 \\
\hline Average number of living children (mean/SD) & 2.8 & 1.6 & 2.4 & 1.6 & 2.1 & 1.7 & 2.3 & 1.9 & 3.1 & 0.9 & 3.2 & 1.2 & 0.1 & 0.95 \\
\hline Proportion with previous miscarriage (N/\%) & 9 & 13.4 & 14 & 10.3 & 11 & 10.1 & 20 & 8.9 & 2 & 5.0 & 18 & 9.5 & 0.3 & 0.76 \\
\hline Proportion with previous stillbirth (N/\%) & 1 & 1.5 & 5 & 3.7 & 2 & 1.8 & 10 & 4.5 & 1 & 2.5 & 6 & 3.2 & -1.4 & 0.17 \\
\hline Proportion with previous premature birth (N/\%) & 5 & 7.5 & 7 & 5.2 & 2 & 1.8 & 13 & 5.8 & 2 & 5.0 & 10 & 5.3 & -0.7 & 0.47 \\
\hline Women exiting ANC services & \multicolumn{2}{|c|}{$n=167$} & \multicolumn{2}{|c|}{$n=221$} & \multicolumn{2}{|c|}{$n=250$} & \multicolumn{2}{|c|}{$n=365$} & \multicolumn{2}{|c|}{$n=99$} & \multicolumn{2}{|c|}{$n=305$} & & \\
\hline Average age in years (mean/SD) & 25.3 & 6.5 & 24.2 & 5.8 & 24.2 & 5.8 & 25.0 & 5.7 & 24.5 & 5.4 & 25.0 & 6.0 & -0.6 & 0.54 \\
\hline Proportion of married women (N/\%) & 163 & 97.6 & 216 & 97.7 & 249 & 99.6 & 356 & 97.5 & 96 & 97.0 & 289 & 94.8 & 0.8 & 0.44 \\
\hline Proportion of literate women (N/\%) & 111 & 66.5 & 146 & 66.1 & 166 & 66.4 & 243 & 66.6 & 52 & 52.5 & 193 & 63.3 & -0.6 & 0.56 \\
\hline Average number of pregnancies (mean/SD) & 3.2 & 2.1 & 2.8 & 1.8 & 1.9 & 1.8 & 2.1 & 1.8 & 3.0 & 1.7 & 2.9 & 1.8 & -0.3 & 0.79 \\
\hline Average number of living children (mean/SD) & 1.9 & 1.9 & 1.5 & 1.6 & 1.7 & 1.6 & 1.8 & 1.6 & 1.8 & 1.5 & 1.7 & 1.6 & 0.7 & 0.46 \\
\hline Proportion with previous miscarriage (N/\%) & 23 & 13.8 & 32 & 14.5 & 23 & 9.2 & 50 & 13.7 & 12 & 12.0 & 30 & 9.8 & -0.7 & 0.46 \\
\hline Proportion with previous stillbirth (N/\%) & 9 & 5.4 & 8 & 3.6 & 11 & 4.4 & 14 & 3.8 & 1 & 1.0 & 13 & 4.3 & 0.1 & 0.90 \\
\hline Proportion with previous premature birth (N/\%) & 9 & 5.4 & 14 & 6.3 & 10 & 4.0 & 11 & 3.0 & 3 & 1.9 & 10 & 3.3 & 0.2 & 0.82 \\
\hline Women exiting PNC services & \multicolumn{2}{|c|}{$n=080$} & \multicolumn{2}{|c|}{$n=150$} & \multicolumn{2}{|c|}{$n=138$} & \multicolumn{2}{|c|}{$n=220$} & \multicolumn{2}{|c|}{$n=077$} & \multicolumn{2}{|c|}{$n=230$} & & \\
\hline Average age in years (mean/SD) & 25.5 & 6.4 & 24.7 & 5.6 & 23.3 & 5.0 & 24.5 & 6.0 & 24.8 & 6.1 & 23.7 & 5.6 & 0.1 & 0.94 \\
\hline Proportion of married women (N/\%) & 78 & 97.5 & 139 & 92.7 & 135 & 97.8 & 212 & 96.4 & 73 & 94.8 & 220 & 95.7 & 1.2 & 0.21 \\
\hline Proportion of literate women (N/\%) & 50 & 62.5 & 91 & 60.7 & 90 & 65.2 & 150 & 68.2 & 43 & 55.8 & 148 & 64.4 & -0.8 & 0.41 \\
\hline Average number of pregnancies (mean/SD) & 3.1 & 2.1 & 2.7 & 1.9 & 3.5 & 1.7 & 3.6 & 1.9 & 3.7 & 1.8 & 3.2 & 1.4 & 2.9 & $0.01^{*}$ \\
\hline Average number of living children (mean/SD) & 2.7 & 1.7 & 2.4 & 1.5 & 2.4 & 1.6 & 2.6 & 1.8 & 3.6 & 1.7 & 3.1 & 1.3 & 1.9 & $0.05^{*}$ \\
\hline Proportion with previous miscarriage (N/\%) & 13 & 16.3 & 19 & 12.7 & 9 & 6.5 & 14 & 6.4 & 3 & 3.9 & 14 & 6.1 & 0.5 & 0.60 \\
\hline Proportion with previous stillbirth (N/\%) & 5 & 6.3 & 4 & 2.7 & 6 & 4.4 & 4 & 1.8 & 2 & 2.6 & 7 & 3.0 & 1.7 & 0.09 \\
\hline Proportion with previous premature birth (N/\%) & 4 & 5.0 & 11 & 7.3 & 6 & 4.4 & 7 & 3.2 & 6 & 7.8 & 10 & 4.4 & 0.6 & 0.52 \\
\hline
\end{tabular}

Effect of RBF4MNH on perceived quality of care We observed no statistically significant change attributable to the RBF4MNH on the quality of care ratings for any of the three dimensions measured (technical care, quality of amenities, interpersonal relations) for any of the three sets of services observed (L\&D, ANC, PNC) (Table 7). We did, however, observe a small decline in perceived quality of care scores in intervention facilities over time, but in the absence of statistical significance, we cannot exclude the possibility that this decline is attributable to sampling errors.

\section{Qualitative findings}

\section{Respondents' characteristic}

Women's age for both IDIs and FGDs varied between 15 and 43 years. The majority of the women were married, literate, had between 1 and 3 children, and all had experienced care at the sampled facilities. The majority of the providers interviewed had worked at the sampled facility 2 to 6 years. All except one had a midwifery diploma.

Appraising the quantitative findings in relation to the qualitative findings both at mid and end terms suggests that women's perceptions of quality of care on the three aspects (i.e. technical care, quality of amenities and interpersonal relations) varied. In contrast with the unanimously positive judgement that emerged from the quantitative scores, the qualitative analysis revealed women's heterogeneous view on quality with some aspects being appreciated and others still being heavily criticized. Over the two data collection rounds, we observed an increased appreciation for services delivered at RBF4MNH facilities as well as a capacity to attribute the changes experienced directly to the intervention. 
Table 4 Impact of RBF4MNH on women's experience of receiving care during labour and delivery

\begin{tabular}{|c|c|c|c|c|c|c|c|c|c|c|c|c|c|c|c|c|}
\hline \multirow[t]{3}{*}{ Indicator } & \multicolumn{4}{|c|}{ Baseline } & \multicolumn{4}{|c|}{ Mid-term } & \multicolumn{4}{|c|}{ End-term } & \multirow{3}{*}{$\begin{array}{l}\text { DID } \\
\text { adjusted } \\
\text { BL-ML }\end{array}$} & \multirow[t]{3}{*}{ Sig. } & \multirow{3}{*}{$\begin{array}{l}\text { DID } \\
\text { adjusted } \\
\text { BL-EL }\end{array}$} & \multirow[t]{3}{*}{ Sig. } \\
\hline & \multicolumn{2}{|c|}{ Comparison } & \multicolumn{2}{|c|}{ Intervention } & \multicolumn{2}{|c|}{ Comparison } & \multicolumn{2}{|c|}{ Intervention } & \multicolumn{2}{|c|}{ Comparison } & \multicolumn{2}{|c|}{ Intervention } & & & & \\
\hline & $\%$ & $N$ & $\%$ & $N$ & $\%$ & $N$ & $\%$ & $N$ & $\%$ & $N$ & $\%$ & $N$ & & & & \\
\hline $\begin{array}{l}\text { Proportion of women reporting } \\
\text { health worker introduction }\end{array}$ & $26 \%$ & 53 & $37 \%$ & 68 & $30 \%$ & 89 & $38 \%$ & 120 & $40 \%$ & 62 & $49 \%$ & 85 & $-4 \%$ & 0.77 & $-4 \%$ & 0.82 \\
\hline $\begin{array}{l}\text { Proportion of women reporting } \\
\text { having been clinically examined }\end{array}$ & $57 \%$ & 53 & $46 \%$ & 68 & $99 \%$ & 89 & $96 \%$ & 120 & $92 \%$ & 62 & $91 \%$ & 85 & $5 \%$ & 0.73 & $6 \%$ & 0.75 \\
\hline $\begin{array}{l}\text { Proportion of women reporting } \\
\text { having received an explanation } \\
\text { of the examination }\end{array}$ & $100 \%$ & 30 & $100 \%$ & 31 & $64 \%$ & 88 & $58 \%$ & 115 & $54 \%$ & 57 & $58 \%$ & 77 & $-5 \%$ & 0.69 & $-2 \%$ & 0.85 \\
\hline $\begin{array}{l}\text { Proportion of women reporting } \\
\text { having received } \\
\text { medication/treatment }\end{array}$ & $92 \%$ & 53 & $71 \%$ & 68 & $87 \%$ & 89 & $88 \%$ & 120 & $66 \%$ & 62 & $79 \%$ & 85 & $23 \%$ & 0.07 & $29 \%$ & $0.03^{*}$ \\
\hline $\begin{array}{l}\text { Proportion of women reporting } \\
\text { having received an explanation } \\
\text { for the medication }\end{array}$ & $59 \%$ & 49 & $63 \%$ & 48 & $42 \%$ & 77 & $46 \%$ & 106 & $56 \%$ & 41 & $73 \%$ & 67 & $-3 \%$ & 0.85 & $12 \%$ & 0.54 \\
\hline $\begin{array}{l}\text { Proportion of women reporting } \\
\text { having had a blood test done }\end{array}$ & $26 \%$ & 53 & $47 \%$ & 68 & $21 \%$ & 89 & $8 \%$ & 120 & $23 \%$ & 62 & $36 \%$ & 85 & $-35 \%$ & 0.03 & $-2 \%$ & 0.90 \\
\hline $\begin{array}{l}\text { Proportion of women reporting } \\
\text { having received an explanation } \\
\text { for the test }\end{array}$ & $93 \%$ & 14 & $75 \%$ & 32 & $32 \%$ & 19 & $30 \%$ & 10 & $64 \%$ & 14 & $65 \%$ & 31 & $9 \%$ & 0.69 & $10 \%$ & 0.65 \\
\hline $\begin{array}{l}\text { Proportion of women reporting } \\
\text { consent being sought before } \\
\text { procedures were performed }\end{array}$ & $55 \%$ & 53 & $61 \%$ & 66 & $62 \%$ & 87 & $63 \%$ & 112 & $68 \%$ & 60 & $75 \%$ & 77 & $-5 \%$ & 0.73 & $1 \%$ & 0.96 \\
\hline $\begin{array}{l}\text { Proportion of women having } \\
\text { been encouraged to ask } \\
\text { questions }\end{array}$ & $36 \%$ & 53 & $49 \%$ & 68 & $25 \%$ & 89 & $33 \%$ & 120 & $45 \%$ & 62 & $58 \%$ & 85 & $-8 \%$ & 0.63 & $2 \%$ & 0.89 \\
\hline $\begin{array}{l}\text { Proportion of women reporting } \\
\text { being offered to have guardian } \\
\text { during delivery }\end{array}$ & $42 \%$ & 53 & $57 \%$ & 68 & $22 \%$ & 89 & $58 \%$ & 120 & $50 \%$ & 62 & $55 \%$ & 85 & $18 \%$ & 0.29 & $3 \%$ & 0.87 \\
\hline $\begin{array}{l}\text { Proportion of women reporting } \\
\text { their privacy/confidentiality } \\
\text { being protected }\end{array}$ & $96 \%$ & 53 & $96 \%$ & 68 & $91 \%$ & 89 & $94 \%$ & 120 & $90 \%$ & 62 & $96 \%$ & 85 & $3 \%$ & 0.67 & $8 \%$ & 0.55 \\
\hline $\begin{array}{l}\text { Proportion of women reporting } \\
\text { blood pressure was checked } \\
\text { before delivery }\end{array}$ & $53 \%$ & 53 & $51 \%$ & 68 & $49 \%$ & 89 & $37 \%$ & 120 & $61 \%$ & 62 & $65 \%$ & 85 & $-15 \%$ & 0.22 & $19 \%$ & 0.26 \\
\hline $\begin{array}{l}\text { Proportion of women reporting } \\
\text { blood pressure was checked } \\
\text { after delivery }\end{array}$ & $40 \%$ & 53 & $44 \%$ & 68 & $66 \%$ & 89 & $57 \%$ & 116 & $45 \%$ & 58 & $68 \%$ & 81 & $-13 \%$ & 0.36 & $19 \%$ & 0.25 \\
\hline
\end{tabular}

$\mathrm{DID}=$ effect estimate based on difference-and-difference regression; $\mathrm{BL}-\mathrm{ML}=$ comparison between cohorts at baseline and mid-term; $\mathrm{BL}-\mathrm{EL}=\mathrm{comparison}$ between cohorts at baseline and end-term; Sig. = significance level of effect estimate

\section{Perceptions of quality changes in technical care (clinical care)}

Although the quantitative findings did not show any measurable change on women's perception of technical care (Table 7), women in our qualitative sample reported that over time they experienced improvements in technical aspects of service delivery when accessing care at RBF4MNH facilities. Most women who utilized services from RBF facilities perceived providers to be competent to carry out different technical care activities.

"Things have changed, like when I was delivering this baby, the nurse was there to assist me. I went to the facility late at night. But before taking off my clothes the baby already came out and had suffocated. But the nurse helped me a lot and the baby got better ... I never thought the baby would survive, but they assured me of my baby's survival". (Woman in FGD, RBF4MNH health facility, end-term)

Furthermore, when comparing women's narratives of the provider patient encounter between midterm and end-term data collection rounds at intervention facilities, we noticed a substantial increase in the proportion of women who reported to have been clinically examined, received medication, and received explanations for the medications. 
Table 5 Impact of RBF4MNH on women's experience of receiving care during ANC

\begin{tabular}{|c|c|c|c|c|c|c|c|c|c|c|c|c|c|c|c|c|}
\hline \multirow[t]{3}{*}{ Indicator } & \multicolumn{4}{|c|}{ Baseline } & \multicolumn{4}{|c|}{ Mid-term } & \multicolumn{4}{|c|}{ End-term } & \multirow{3}{*}{$\begin{array}{l}\text { DID } \\
\text { adjusted } \\
\text { BL-ML }\end{array}$} & \multirow[t]{3}{*}{ Sig. } & \multirow{3}{*}{$\begin{array}{l}\text { DID } \\
\text { adjusted } \\
\text { BL-EL }\end{array}$} & \multirow[t]{3}{*}{ Sig. } \\
\hline & \multicolumn{2}{|c|}{ Comparison } & \multicolumn{2}{|c|}{ Intervention } & \multicolumn{2}{|c|}{ Comparison } & \multicolumn{2}{|c|}{ Intervention } & \multicolumn{2}{|c|}{ Comparison } & \multicolumn{2}{|c|}{ Intervention } & & & & \\
\hline & $\%$ & $N$ & $\%$ & $N$ & $\%$ & $N$ & $\%$ & $N$ & $\%$ & $N$ & $\%$ & $N$ & & & & \\
\hline $\begin{array}{l}\text { Proportion of women reporting } \\
\text { health worker introduction }\end{array}$ & $34 \%$ & 152 & $51 \%$ & 128 & $49 \%$ & 223 & $53 \%$ & 244 & $43 \%$ & 133 & $61 \%$ & 135 & $-12 \%$ & 0.37 & $-9 \%$ & 0.56 \\
\hline $\begin{array}{l}\text { Proportion of women reporting } \\
\text { having been clinically examined }\end{array}$ & $98 \%$ & 152 & $98 \%$ & 128 & $99 \%$ & 223 & $96 \%$ & 244 & $96 \%$ & 133 & $98 \%$ & 135 & $-3 \%$ & 0.19 & $5 \%$ & 0.39 \\
\hline $\begin{array}{l}\text { Proportion of women reporting } \\
\text { having received an explanation } \\
\text { of the examination }\end{array}$ & $72 \%$ & 149 & $84 \%$ & 126 & $67 \%$ & 221 & $70 \%$ & 235 & $80 \%$ & 128 & $83 \%$ & 132 & $-7 \%$ & 0.53 & $1 \%$ & 0.94 \\
\hline $\begin{array}{l}\text { Proportion of women reporting } \\
\text { having received } \\
\text { medication/treatment }\end{array}$ & $96 \%$ & 152 & $93 \%$ & 128 & $86 \%$ & 223 & $87 \%$ & 244 & $93 \%$ & 133 & $93 \%$ & 135 & $4 \%$ & 0.62 & $-4 \%$ & 0.43 \\
\hline $\begin{array}{l}\text { Proportion of women reporting } \\
\text { having received an explanation } \\
\text { for the medication }\end{array}$ & $84 \%$ & 146 & $86 \%$ & 119 & $75 \%$ & 191 & $71 \%$ & 213 & $90 \%$ & 124 & $94 \%$ & 126 & $-8 \%$ & 0.43 & $2 \%$ & 0.71 \\
\hline $\begin{array}{l}\text { Proportion of women reporting } \\
\text { having had a blood test done }\end{array}$ & $74 \%$ & 152 & $68 \%$ & 128 & $37 \%$ & 223 & $36 \%$ & 244 & $69 \%$ & 133 & $68 \%$ & 135 & $6 \%$ & 0.69 & $-2 \%$ & 0.91 \\
\hline $\begin{array}{l}\text { Proportion of women reporting } \\
\text { having received an explanation } \\
\text { for the test }\end{array}$ & $95 \%$ & 113 & $94 \%$ & 87 & $78 \%$ & 82 & $86 \%$ & 87 & $96 \%$ & 92 & $90 \%$ & 92 & $12 \%$ & 0.18 & $-1 \%$ & 0.84 \\
\hline $\begin{array}{l}\text { Proportion of women reporting } \\
\text { having had any clinical } \\
\text { procedures performed }\end{array}$ & $98 \%$ & 152 & $100 \%$ & 128 & $99 \%$ & 223 & $98 \%$ & 244 & $100 \%$ & 133 & $100 \%$ & 135 & $-3 \%$ & 0.09 & $-3 \%$ & 0.11 \\
\hline $\begin{array}{l}\text { Proportion of women reporting } \\
\text { consent being sought before } \\
\text { procedures were performed }\end{array}$ & $68 \%$ & 149 & $77 \%$ & 128 & $73 \%$ & 221 & $74 \%$ & 239 & $82 \%$ & 133 & $91 \%$ & 135 & $-8 \%$ & 0.41 & $3 \%$ & 0.72 \\
\hline $\begin{array}{l}\text { Proportion of women having } \\
\text { been encouraged to ask } \\
\text { questions }\end{array}$ & $61 \%$ & 152 & $71 \%$ & 128 & $55 \%$ & 223 & $58 \%$ & 244 & $73 \%$ & 133 & $80 \%$ & 135 & $-8 \%$ & 0.52 & $6 \%$ & 0.57 \\
\hline $\begin{array}{l}\text { Proportion of women having } \\
\text { been offered to have a guardian }\end{array}$ & $53 \%$ & 152 & $61 \%$ & 128 & $36 \%$ & 223 & $71 \%$ & 244 & $80 \%$ & 133 & $70 \%$ & 135 & $29 \%$ & 0.04 & $-7 \%$ & 0.60 \\
\hline $\begin{array}{l}\text { Proportion of women reporting } \\
\text { their privacy \& confidentiality } \\
\text { being protected }\end{array}$ & $97 \%$ & 152 & $99 \%$ & 128 & $95 \%$ & 223 & $98 \%$ & 244 & $94 \%$ & 133 & $94 \%$ & 135 & $1 \%$ & 0.65 & $3 \%$ & 0.72 \\
\hline $\begin{array}{l}\text { Proportion of women reporting } \\
\text { blood pressure having } \\
\text { been checked }\end{array}$ & $54 \%$ & 152 & $82 \%$ & 128 & $73 \%$ & 223 & $56 \%$ & 240 & $69 \%$ & 130 & $71 \%$ & 135 & $-47 \%$ & 0.01 & $-28 \%$ & 0.10 \\
\hline
\end{tabular}

$\mathrm{DID}=$ effect estimate based on difference-and-difference regression; BL-ML = comparison between cohorts at baseline and mid-term; BL-EL = comparison between cohorts at baseline and end-term; Sig. = significance level of effect estimate

"They do not explain everything most of times we are told to lay on the bed and they examine what they know without informing us. And after examination we are given medication". (Woman in FGD, RBF4MNH health facility, mid-term)

"After ANC Examination, the health worker informed me well about the condition of the baby and me. The health worker also asked me if the baby was kicking in the womb and I said yes. And thereafter I was given information about the medication and they taught me the importance of the medication. They said that it helps to increase blood because during delivery women lose blood. So I was encouraged to take medication as it was prescribed to me.
In fact, the provider was a caring person. But I do not know if my fellow women were also treated like this".

(Woman in FGD, RBF4MNH health facility, end-term)

Providers at intervention facilities confirmed women's observations by indicating that they felt more secure in their skills and by reporting greater adherence to recommended standards of care following the introduction of the RBF4MNH Initiative. The vast majority of providers at intervention facilities attributed the change to the trainings and increased supervision offered under the RBF4MNH Initiative.

"... most of the training which I have done it's because of $R B F$, neonatal and maternal care, is been done because of RBF, as of now, am 
Table 6 Impact of RBF4MNH on women's experience of receiving care during PNC

\begin{tabular}{|c|c|c|c|c|c|c|c|c|c|c|c|c|c|c|c|c|}
\hline \multirow[t]{3}{*}{ Indicator } & \multicolumn{4}{|c|}{ Baseline } & \multicolumn{4}{|c|}{ Mid-term } & \multicolumn{4}{|c|}{ End-term } & \multirow{3}{*}{$\begin{array}{l}\text { DID } \\
\text { adjusted } \\
\text { BL-ML }\end{array}$} & \multirow[t]{3}{*}{ Sig. } & \multirow{3}{*}{$\begin{array}{l}\text { DID } \\
\text { adjusted } \\
\text { BL-EL }\end{array}$} & \multirow{3}{*}{ Sig. } \\
\hline & \multicolumn{2}{|c|}{ Comparison } & \multicolumn{2}{|c|}{ Intervention } & \multicolumn{2}{|c|}{ Comparison } & \multicolumn{2}{|c|}{ Intervention } & \multicolumn{2}{|c|}{ Comparison } & \multicolumn{2}{|c|}{ Intervention } & & & & \\
\hline & $\%$ & $N$ & $\%$ & $N$ & $\%$ & $N$ & $\%$ & $N$ & $\%$ & $N$ & $\%$ & $N$ & & & & \\
\hline $\begin{array}{l}\text { Proportion of women reporting } \\
\text { health worker introduction }\end{array}$ & $40 \%$ & 63 & $49 \%$ & 106 & $36 \%$ & 136 & $34 \%$ & 142 & $34 \%$ & 109 & $50 \%$ & 103 & $-11 \%$ & 0.59 & $2 \%$ & 0.92 \\
\hline $\begin{array}{l}\text { Proportion of women reporting } \\
\text { having been clinically examined }\end{array}$ & $90 \%$ & 63 & $67 \%$ & 106 & $74 \%$ & 136 & $56 \%$ & 142 & $65 \%$ & 109 & $74 \%$ & 103 & $5 \%$ & 0.76 & $35 \%$ & 0.09 \\
\hline $\begin{array}{l}\text { Proportion of women reporting } \\
\text { having received an explanation } \\
\text { of the examination }\end{array}$ & $68 \%$ & 57 & $67 \%$ & 71 & $65 \%$ & 100 & $60 \%$ & 80 & $84 \%$ & 71 & $63 \%$ & 76 & $-4 \%$ & 0.80 & $-20 \%$ & 0.11 \\
\hline $\begin{array}{l}\text { Proportion of women reporting } \\
\text { having received } \\
\text { medication/treatment }\end{array}$ & $49 \%$ & 63 & $42 \%$ & 106 & $30 \%$ & 136 & $23 \%$ & 142 & $44 \%$ & 109 & $36 \%$ & 103 & $0.2 \%$ & 0.99 & $-15 \%$ & 0.48 \\
\hline $\begin{array}{l}\text { Proportion of women reporting } \\
\text { having received an explanation } \\
\text { for the medication }\end{array}$ & $68 \%$ & 31 & $87 \%$ & 45 & $63 \%$ & 41 & $63 \%$ & 32 & $74 \%$ & 48 & $64 \%$ & 37 & $-20 \%$ & 0.30 & $-29 \%$ & 0.10 \\
\hline $\begin{array}{l}\text { Proportion of women reporting } \\
\text { having had a blood test done }\end{array}$ & $25 \%$ & 63 & $20 \%$ & 106 & $4 \%$ & 136 & $3 \%$ & 142 & $11 \%$ & 109 & $20 \%$ & 103 & $5 \%$ & 0.71 & $4 \%$ & 0.78 \\
\hline $\begin{array}{l}\text { Proportion of women reporting } \\
\text { having received an explanation } \\
\text { for the test }\end{array}$ & $94 \%$ & 16 & $95 \%$ & 21 & $17 \%$ & 6 & $50 \%$ & 4 & $83 \%$ & 12 & $86 \%$ & 21 & $22 \%$ & 0.43 & $3 \%$ & 0.83 \\
\hline $\begin{array}{l}\text { Proportion of women reporting } \\
\text { having had any clinical } \\
\text { procedures performed }\end{array}$ & $90 \%$ & 63 & $75 \%$ & 106 & $75 \%$ & 136 & $58 \%$ & 142 & $67 \%$ & 109 & $82 \%$ & 103 & $0.3 \%$ & 0.99 & $25 \%$ & 0.10 \\
\hline $\begin{array}{l}\text { Proportion of women reporting } \\
\text { consent being sought before } \\
\text { procedures were performed }\end{array}$ & $68 \%$ & 57 & $68 \%$ & 79 & $63 \%$ & 102 & $61 \%$ & 83 & $81 \%$ & 73 & $77 \%$ & 84 & $-7 \%$ & 0.69 & $2 \%$ & 0.94 \\
\hline $\begin{array}{l}\text { Proportion of women having } \\
\text { been encouraged to ask } \\
\text { questions }\end{array}$ & $65 \%$ & 63 & $50 \%$ & 105 & $35 \%$ & 136 & $36 \%$ & 142 & $53 \%$ & 109 & $61 \%$ & 103 & $17 \%$ & 0.33 & $23 \%$ & 0.25 \\
\hline $\begin{array}{l}\text { Proportion of women having } \\
\text { been offered to have a guardian }\end{array}$ & $47 \%$ & 62 & $39 \%$ & 102 & $21 \%$ & 136 & $23 \%$ & 142 & $39 \%$ & 109 & $33 \%$ & 103 & $8 \%$ & 0.60 & $-2 \%$ & 0.92 \\
\hline $\begin{array}{l}\text { Proportion of women reporting } \\
\text { their privacy \& confidentiality } \\
\text { being protected }\end{array}$ & $95 \%$ & 63 & $96 \%$ & 106 & $88 \%$ & 136 & $92 \%$ & 142 & $88 \%$ & 109 & $89 \%$ & 103 & $1 \%$ & 0.94 & $7 \%$ & 0.54 \\
\hline $\begin{array}{l}\text { Proportion of women reporting } \\
\text { blood pressure having } \\
\text { been checked }\end{array}$ & $51 \%$ & 63 & $39 \%$ & 106 & $30 \%$ & 136 & $28 \%$ & 142 & $52 \%$ & 109 & $56 \%$ & 103 & $9 \%$ & 0.73 & $10 \%$ & 0.74 \\
\hline $\begin{array}{l}\text { Proportion of women reporting } \\
\text { baby's weight was checked }\end{array}$ & $90 \%$ & 63 & $74 \%$ & 106 & $80 \%$ & 136 & $70 \%$ & 142 & $69 \%$ & 109 & $75 \%$ & 103 & $6 \%$ & 0.64 & $23 \%$ & 0.27 \\
\hline
\end{tabular}

$\mathrm{DID}=$ effect estimate based on difference-and-difference regression; BL-ML = comparison between cohorts at baseline and mid-term; BL-EL = comparison between cohorts at baseline and end-term; Sig. = significance level of effect estimate

competent compared to the way I was before.

I can manage some of the conditions which were difficult to be managed... I am competent enough to do such things". (Skilled birth attendant at an RBF4MNH health facility, end-term)

If on one side, women at intervention facilities reported being examined and treated more accurately, on the other side, women also reported concerns in relation to procedures whose objective was not clear to them. For instance, women repeatedly referred to the more accurate removal of the retained products of conception (an infection prevention procedure) promoted by the RBF4MNH Initiative as "mopping the uterus" and at times attributed a sinister meaning to it.

"In the previous deliveries, they were not cleaning our womb and the remaining things were coming out without them cleaning us. They were only giving us injection after delivery. So I complained to them that the process is painful and the health worker responded to me that this is going to help me to have good health when I get home". (Woman in FGD, RBF4MNH health facility, end-term) 
Table 7 Impact of RBF4MNH on perceived quality of care for labour and delivery, ANC and PNC services

\begin{tabular}{|c|c|c|c|c|c|c|c|c|c|c|c|c|c|c|c|c|}
\hline \multirow[t]{3}{*}{ Indicator } & \multicolumn{4}{|c|}{ Baseline } & \multicolumn{4}{|c|}{ Midline } & \multicolumn{4}{|c|}{ Endline } & \multirow{3}{*}{$\begin{array}{l}\text { DID } \\
\text { adjusted } \\
\text { BL-ML }\end{array}$} & \multirow[t]{3}{*}{ Sig. } & \multirow{3}{*}{$\begin{array}{l}\text { DID } \\
\text { adjusted } \\
\text { BL-EL }\end{array}$} & \multirow[t]{3}{*}{ Sig. } \\
\hline & \multicolumn{2}{|c|}{ Control } & \multicolumn{2}{|c|}{ Intervention } & \multicolumn{2}{|c|}{ Control } & \multicolumn{2}{|c|}{ Intervention } & \multicolumn{2}{|c|}{ Control } & \multicolumn{2}{|c|}{ Intervention } & & & & \\
\hline & Mean & N & Mean & $N$ & Mean & N & Mean & $N$ & Mean & $N$ & Mean & $N$ & & & & \\
\hline \multicolumn{17}{|l|}{ Labour and delivery services } \\
\hline $\begin{array}{l}\text { Mean score of women's } \\
\text { perceptions on interpersonal } \\
\text { relations }\end{array}$ & 9.3 & 52 & 9.2 & 68 & 9.3 & 89 & 8.7 & 120 & 9.3 & 62 & 8.9 & 85 & -0.5 & 0.13 & -0.1 & 0.70 \\
\hline $\begin{array}{l}\text { Mean score of women's } \\
\text { perceptions on quality } \\
\text { of amenities }\end{array}$ & 9.3 & 51 & 9.5 & 68 & 9.5 & 89 & 9.2 & 120 & 9.3 & 62 & 9.2 & 85 & -0.6 & 0.07 & -0.3 & 0.45 \\
\hline $\begin{array}{l}\text { Mean score of women's } \\
\text { perceptions on technical care }\end{array}$ & 9.3 & 51 & 9.2 & 68 & 9.3 & 89 & 8.8 & 120 & 9.1 & 62 & 8.7 & 85 & -0.5 & 0.22 & -0.1 & 0.85 \\
\hline \multicolumn{17}{|l|}{ Antenatal care services } \\
\hline $\begin{array}{l}\text { Mean score of women's } \\
\text { perceptions on } \\
\text { interpersonal relations }\end{array}$ & 9.2 & 152 & 9.1 & 127 & 9.2 & 223 & 8.9 & 244 & 9.2 & 133 & 9.3 & 135 & -0.2 & 0.51 & -0.2 & 0.56 \\
\hline $\begin{array}{l}\text { Mean score of women's } \\
\text { perceptions on quality of } \\
\text { amenities }\end{array}$ & 9.5 & 152 & 9.4 & 127 & 9.4 & 223 & 9.2 & 244 & 9.4 & 133 & 9.2 & 135 & -0.1 & 0.71 & -0.2 & 0.54 \\
\hline $\begin{array}{l}\text { Mean score of women's } \\
\text { perceptions on technical care }\end{array}$ & 9.2 & 152 & 9.0 & 127 & 9.1 & 223 & 8.8 & 244 & 9.0 & 133 & 8.7 & 135 & -0.1 & 0.74 & -0.2 & 0.39 \\
\hline \multicolumn{17}{|l|}{ Postnatal care services } \\
\hline $\begin{array}{l}\text { Mean score of women's } \\
\text { perceptions on } \\
\text { interpersonal relations }\end{array}$ & 9.1 & 63 & 9.0 & 105 & 9.0 & 136 & 8.9 & 142 & 9.2 & 109 & 9.0 & 103 & -0.1 & 0.73 & -0.30 & 0.45 \\
\hline $\begin{array}{l}\text { Mean score of women's } \\
\text { perceptions on quality } \\
\text { of amenities }\end{array}$ & 9.3 & 63 & 9.2 & 105 & 9.3 & 136 & 9.2 & 142 & 9.3 & 109 & 9.1 & 103 & -0.1 & 0.76 & -0.49 & 0.14 \\
\hline $\begin{array}{l}\text { Mean score of women's } \\
\text { perceptions on technical care }\end{array}$ & 8.9 & 63 & 8.8 & 105 & 9.0 & 136 & 8.8 & 142 & 8.7 & 109 & 8.6 & 103 & -0.1 & 0.78 & -0.31 & 0.38 \\
\hline
\end{tabular}

$\mathrm{DID}=$ effect estimate based on difference-and-difference regression; $\mathrm{BL}-\mathrm{ML}=$ comparison between cohorts at baseline and mid-term; $\mathrm{BL}-\mathrm{EL}=\mathrm{comparison}$ between cohorts at baseline and end-term; Sig. = significance level of effect estimate

Similarly, women displayed little appreciation for some procedures, such as consent seeking, which increased across intervention and control facilities over time (Tables 4, 5 and 6). When asked consent seeking, women postulated concerns that this was necessary at all, since to them, seeking care was per se an expression of consent.

"When one is going for ANC you are prepared knowing that where I am going I will be touched in such a way. So I feel there is no need for consent seeking". (Woman in FGD, RBF4MNH health facility, end-term)

While women at intervention facilities reported considerable improvements in ANC and delivery care, women at both intervention and control facilities continued to be dissatisfied with PNC. Most women indicated that at the PNC encounters, they received no care and even babies were checked only superficially.

"I did not spend much time during the PNC consultation because the health worker only checked the navel of my baby". (Woman in FGD, non-RBF4MNH health facility, mid-term)

"When I went to the hospital to show my child after one week, the nurse just looked at my child and told me that my child was fine. The child was never weighed and the navel was never checked to see if it had healed". (Woman in FGD, RBF4MNH health facility, end-term)

"When I went to the hospital to show my child after one week, the nurse just looked at my child and told me that my child was fine. The child was never weighed and the navel was never checked to see if it had healed". (Woman in FGD, RBF4MNH health facility, end-term)

\section{Perceptions of quality changes in amenities (service infrastructure)}

While respondents from control health facilities complained of scarcity of basic resources, respondents from intervention facilities appreciated the availability of equipment, drugs, enhanced visual privacy (through the 
use of screens) and infection prevention supplies at both mid-term and end-term periods.

"The equipments are not adequate. We are told to bring a razor blade, plastic sheet/paper and a piece of cloth. There is also need to add the number of nurses at the facility". (Woman in FGD, non-RBF4MNH health facility, mid-term)

"Our facility is different from how it used to be. Now the environment is looking good. Resources and equipment are also available. Previously, when some of us delivered there, we were told that the facility lacked important equipment." (Woman in FGD, RBF4MNH health facility, end-term)

Women at intervention facilities also appreciated positive changes in hygiene and cleanliness, which were not reported by women at control facilities.

"Compared to the past, there is cleanliness in the facility. It is well mopped and clean. There is no bad smell like in other hospitals. The cleaners are really doing a good job. They clean the bathrooms and the toilets in the morning and in the evening leaving the premises clean as they knock off [..]. There are even bins inside which are used to throw in any trash and this is also enhancing the cleanliness at the hospital". (Woman in FGD, RBF4MNH health facility, end-term)

Most providers agreed with the women's observations and indicated that an increased availability of resources (i.e. drugs and supplies) and infrastructure upgrades due to the RBF4MNH Initiative had made it possible for them to improve service delivery. Despite the reported improvements, most providers at $\mathrm{BEmOC}$ intervention facilities indicated that they still struggled for bed space due a high caseload and to the increase in demand which followed the introduction of the RBF4MNH.

"[...] we have three beds, but we actually have most of the times seven, six, five women delivering at one time - three on the bed, two or three or four on the floor. So when helping a woman while on the floor, sometimes we take risks and it's so tiresome. That's the challenge." (Skilled birth attendant at an RBF4MNH health facility, end-term)

\section{Perception of changes in interpersonal care (provider-patient interactions)}

A comparison between mid-term and end-term qualitative data provides an indication of improvements in provider-patient interactions in RBF4MNH facilities. At mid-term, the majority of women both at intervention and at control facilities recounted being verbally abused during childbirth.

"... the nurse pushed me out of the door and asked me the number of deliveries I have ever had and I informed her that this was my sixth delivery. She shouted at me, said that I was lying, "this is your tenth delivery and with the problem you have [the woman was HIV positive] you are not supposed to give birth again". And I was told to deliver alone. Fortunately I delivered a live baby. Then the nurse came and took care of the baby. So this was painful to me". (Woman in FGD, RBF4MNH health facility, mid-term)

"The health workers are mistreating us. For instance when a patient has called for help they ignore by saying I was not there when you were having sex with your husband". (Woman in FGD, non-RBF4MNH health facility, mid-term)

At end-term, most women from intervention facilities reported positive experiences in relation to their interaction with providers. However, some women reported continued instances of disrespect and verbal abuse by some selected providers whereby unpalatable language was used.

"... they were busy passing us and shouting, using obscene language telling me to dress up, saying, "go away, don't show us your dirty and stinking..." they speak such kind of languages; we have no choice but to endure such abuse, since there is nothing we can do... when we are in the labour room, what we need is just to be assisted. So we put up with their actions, because we know we can't talk back since they are doctors, we fear that if we answer back they may never help us ..." (Woman in FGD, RBF4MNH health facility, end-term)

Further, both at mid-term and at end-term and both in intervention and control facilities, a few women reported having been ignored or not monitored during labour, ending up giving birth alone or with assistance from cleaners or guardians. Many women criticized a common tendency among providers to send them back from labour wards towards the waiting premises without first examining them. Therefore, some women reported to have given birth outside the labour ward or having been rushed back into the labour ward, and in some instances, babies were reported to have fallen on the floor.

"... but when she was getting back on her bed, just after her one leg reached the bed, the baby came out with force and fell on the floor, it was me who screamed to the provider saying the girl has delivered and the baby has fallen down. To my dismay, instead 
of the provider rushing to pick the baby, the provider stood and started shouting at the girl. "Didn't you know that down there something is coming out" the baby was there down rolling. It was me who told the girl, "Girl, if you have some energy please get down and carry your baby, it's your baby". The girl got down and picked up her baby...." (Woman in FGD, RBF4MNH health facility, end-term)

In response to instances of verbal abuse, providers confirmed that indeed there are a few "rotten apples" that tarnish the image of all health providers. However, providers at intervention facilities indicated that through the client satisfaction surveys introduced by the RBF4MNH Initiative, facilities receive feedback on issues of concern (e.g. verbal abuse) and make necessary changes to incorporate women's voices in health care provision.

"yaa..For us staff we usually not speak well so because of that the mothers keep this in their mind that when I will go to the hospital this is the treatment I am going to get". (Skilled birth attendant at an RBF4MNH health facility, mid-term)

"I can say may be we have improved a little because when women get discharged they respond to a questionnaire asking them what challenges they have met and the experience they had in the past pregnancy and now. Now care is improved a little more compared to the past pregnancy even though there are some hiccups they say this". (Skilled birth attendant at an RBF4MNH health facility, end-term)

In response to neglected care, many providers in both intervention and comparison facilities indicated that monitoring the women was difficult due to large workloads, especially because they were running integrated care services: maternal care (i.e. labour and delivery, ANC and PNC), family planning clinics and blood screening (e.g. for HIV and syphilis). They pointed out that in cases where a provider is working alone, they failed to give exclusive attention to labouring women since they were taking care of other services. As a result, some women could not be closely monitored and sometimes, though not often, they would give birth unattended. Providers themselves recognized this as a major hindrance to ensuring quality in service delivery, especially at $\mathrm{CEmOC}$ facilities where workload is greater.

\section{Discussion}

The fundamental question addressed in this study was whether the RBF4MNH Initiative (including both PBF and (CT) had an effect on women's experiences and perceptions of quality of maternal and newborn care services. In the context of this study, we explored three dimensions of women's perceived QoC: technical care (clinical care); quality of amenities in the facilities, and quality of interpersonal relations (provider-patient interactions) and measured each dimension along the continuum of care from ANC to L\&D to PNC. In addition, we reconstructed women's experiences of care through a detailed structured recall of women's interaction with providers. We complemented both sets of quantitative data with qualitative data originating from interviews and FGD with women and their providers.

Our quantitative analysis did not detect a significant effect of the RBF4MNH on any of the three dimensions of quality or for any of the services observed. Similarly, our models only detected a handful of significant effects on women's experiences of care. These findings appear surprising in the light of the fact that qualitative findings are indicative of a much more complex scenario, characterized by a mixture of positive and negative experiences and perceptions in relation to the quality of service provision and to the changes produced by the RBF4MNH Initiative. In spite of reporting considerable improvements following the introduction of the RBF4MNH Initiative, women noted that instances of disrespect, at times leading to overt abuse, continued to overshadow their experiences of care.

This apparent incongruence between quantitative and qualitative findings deserves attention and requires that we take a critical look at the tools we used to quantify experiences and perceived quality of service provision, drawing some important lessons for future research. The lack of effect observed across all scores measuring quality of care can largely be attributed to the high values already recorded at baseline. Detecting further improvements with an average baseline value of 9 would have required either a much larger sample (allowing us to detect changes of even small magnitude as significant) or a change of a considerable magnitude (with women consistently rating quality of care at 10). In addition, as noted in a prior publication [43] and in line with what was observed elsewhere [51], these consistently high ratings are an indication that rural Malawian women struggled to rate quality of service provision along a quantitative scale. In spite of our explicit efforts to develop a culturally sensitive tool (including the use of a visual aid to facilitate rating) [43], this difficulty calls into question the applicability of this approach in rural SSA and should encourage researchers to develop alternative quantitative tools to elicit ratings in these settings beyond the ones currently available.

An additional methodological considerations to be taken into account when appraising our quantitative findings derives from the fact that we cannot exclude 
that women's high ratings of quality of service provision might have been influenced by fear of future repercussions from service providers, since we conducted our exit interviews at the health facilities [43]. Furthermore, we acknowledge the potential of a Hawthorne effect [52], with providers modifying their behaviour for the better during our limited stay at the facility. We also acknowledge that women might have faced difficulties in properly recounting and assessing some dimensions included in our structured survey (e.g. health workers honesty, competency, co-ordination and sufficiency of equipment in the delivery room), since during a structured interview, the enumerator does not engage extensively with respondents to contextualize questions and probe for answers, as it is instead the case during a qualitative encounter [41].

The inability to detect an effect on women's experience of care may also be influenced by our study design and by the overall socio-economic context surrounding the implementation of the RBF4MNH Initiative. A closer look at the quantitative findings on women's experience of care suggests that change occurred on several dimensions, but did so in an equal manner across intervention and control facilities (e.g. probability of having been clinically examined during L\&D). Such an observation normally indicates that change was influenced by a secular trend and that a given intervention did not produce any additional benefit. In our specific case, however, we have reason to believe that the secular trend itself was influenced by the intervention, since, as described earlier, the RBF4MNH Initiative included incentives beyond the single facilities, targeting directly the District Health Management Teams. These incentives, linked to the management team's supervisory role and to the overall district performance, are likely to have produced changes across intervention and control facilities, since the management teams worked to improve overall performance at a district level. Selecting control facilities outside the concerned districts would have allowed us to bypass this challenge and better discern the effect of the intervention, but this strategy was not feasible due to political and operational concerns (other health interventions supported by other development partners were planned in neighboring districts, thus the $\mathrm{MoH}$ could not grant us permission to include them as controls). At the same time, one needs to consider that the decline observed on some dimensions of care across intervention and control facilities (e.g. probability of receiving medication during $\mathrm{PNC}$ ) was probably due to the fact that the RBF4MNH Initiative was implemented at a time when Malawi was suffering from a major economic crisis [53] during which public resources for the health sector shrank considerably, further limiting supplies for intervention and control facilities alike. These considerations are not meant to cast doubt on the validity of our study, but rather to allow the reader to contextualize the quantitative findings, looking for meaning beyond the mere percentage change and statistical significance detected by our models.

We did, however, identify change attributable to the intervention on a few selected items related to women's experience of care. Apart from the clinical relevance of the single procedures (which is a subject beyond the scope of our investigation in this study), we observed that while the probability of having one's blood pressure taken during ANC decreased as a function of the intervention, the probability of being asked whether the patient would like to keep a companion during ANC and of receiving drugs during delivery increased. Complementing the quantitative findings, women's narrative accounts in our qualitative findings provided indications that the greatest improvements in experiences and quality of service delivery were in relation to improved perceived providers' competence and service infrastructure. In relation to providers' competence, women appreciated that physical examinations were conducted; procedures and purpose of medication were explained. For service infrastructure, women appreciated that the facilities were kept clean and hygienic and that drugs, equipment and other essential supplies were readily available and that the women's privacy was respected. These results indicate the potential of the RBF4MNH to improve women's satisfaction and in turn service use, given that several prior studies have demonstrated perceived staff competency (i.e. knowledgeable and qualified providers) and service infrastructure (i.e. a health facility that is tidy, clean and with adequate drugs and supplies) to be important factors in shaping clients' satisfaction and service use [29, 54-59].

Providers confirmed women's reports by explaining how the RBF4MNH Initiative had contributed towards producing these changes. They indicated that the improved availability of resources represented a positive change, especially in a country like Malawi, where equipment and supply shortages represent the primary source of public outcry and healthcare providers' frustration [35]. Two parallel evaluations, one looking at the impact of RBF4MNH on clinical processes of care and one exploring health-care workers' motivation in the context of RBF4MNH, confirm that the availability of equipment and supplies eased the pressure on healthcare providers and enhanced their ability to provide quality services (Brenner et al., under review Bull World Health Organ; Lohmann et al., in preparation). Our findings are not surprising and perfectly aligned with the literature indicating that equipped facilities strengthen the health system [60] and improve women's perceptions regarding maternal care ([69], [61, 62]) and demand for services [59]. 
In spite of the improvements experienced as a consequence of the RBF4MNH Initiative, it is worrisome and worth the consideration of policy makers that women continued to report instances of disrespect and abuse (D\&A), with some women reporting being verbally abused and neglected even under RBF4MNH. Beyond the need to provide care that meets high clinical standards, the international maternal care community unanimously recognizes women's right to be treated with respect throughout the delivery and childbirth experience [63]. Consensus on the value of providing respectful care has emerged as the literature confirmed that the display of D\&A behaviours by providers may instil fear in women [60] and affect their satisfaction and subsequent use of the health services [60, 64, 65]. Further, neglectful behaviour may instil a feeling of hopelessness which may lead to postpartum depression or stress disorder $[66,67]$.

The health-care providers' interviews draw a differentiation between neglectful and abusive behaviours. On the one side, they recognized that perceived neglect may arise as they are called to assist to too many patients at once, thus they simply lack capacity to monitor each labouring woman closely. They explained that the human resource investments brought about by the RBF4MNH were not sufficient to compensate for the increase in workload that followed the implementation of the intervention. This concern with workload needs to be addressed in a prompt manner for the good of clients, but also for the good of providers, since the literature already indicates how providers' frustration with inefficiencies in health system structures can easily lead to poor patient-provider interactions [60]. On the other side, the providers we interviewed distanced themselves from the instances of abuse reported by women and attributed them to single providers, who are accused of "spoiling" the name of all providers in the country.

Given the absence of comparable studies exploring experiences of care and perceptions of quality of service delivery within the context of a PBF intervention, it is difficult to gauge to what extent the concerns raised by women in our study are shared in other settings where PBF has been implemented. To our knowledge, however, currently active PBF programs, including the RBF4MNH Initiative, reward improvements in infrastructural and process dimensions of care, but still struggle to set incentives to target directly the provider-patient interaction. As such, in the absence of a specific strategy targeting the interpersonal dimension of care, PBF is unlikely to motivate a behavioural change that leads to improvements in the provider-patient interactions. This difficulty is further enhanced by the fact that providers engaged in PBF programs often face an increased demand for services. In a setting with relatively high baseline workload such as Malawi, resulting excessive workload can thus pose a threat to the motivational benefits generated by the incentives, the increased autonomy and the supervision granted by PBF, as for instance reported from Rwanda [68] and Nigeria [69].

The fact that our results on interpersonal relations reflect the status quo (that of D\&A) as observed in the literature $[37,38,61]$ suggests that $D \& A$ is a common concern in Malawi and that the RBF4MNH did not include a sufficient number of instruments to counteract this phenomenon. This is somewhat surprising given the emphasis placed by the programme on hearing women's voices, for instance through the inclusion of client exit interviews (satisfaction surveys) in the programme's regular review cycle. Therefore, we urge policy makers and project implementers to consider additional means/specific indicators to counter D\&A and stimulate provision of respectful maternal care. Discussion should be initiated in this RBF as well as in parallel ones across SSA on how to integrate an additional set of targets and related indicators to promote provision of respectful maternal care.

\section{Conclusion}

Overall, we found no effect of the RBF4MNH Initiative on perceived quality of care. However, we did find intervention effects on certain elements of women's experience of care. Our qualitative results also suggest positive improvements in respect to availability of equipment, drugs, supplies, and facility cleanliness. However, there were continued instances of D\&A even under the RBF4MNH Initiative, largely influenced by perceived staff shortages and high workload on the part of the providers. Current and future RBF interventions should ensure that besides the provision of material resources, the quantity of human resources available to provide quality care should be sufficient. In addition, issues of D\&A deserve attention from policy makers. RBF interventions should consider incentivising positive attitudes among providers and adopt rights-based-approaches to defend human dignity and provide women with their basic fundamental human rights [55].

\footnotetext{
Abbreviations

ANC: Antenatal Clinic; CCT: Conditional Cash Transfer; CEmOC: Comprehensive Emergency Obstetric Care; COMREC: College of Medicine Research and Ethics Committee; DCs: District Commissioners; DHOs: District Health Officers; DID: Difference in Difference; EmONC: Emergency obstetric and neonatal care; FGD: Focus Group Discussion; IDI: In-Depth Interviews; IP: Infection prevention; LMICs: Low and middle income countries; MMR: Maternal Mortality Ratio; MNH: Maternal and Newborn Health; MoH: Ministry of Health; NMR: Neonatal Mortality Rate; OLS: Ordinary Least Squares; PBF: Performance Based Financing; PNC: Postnatal care; QoC: Quality of care; RBF4MNH: Results Based Financing for Maternal and Newborn Health; RHU: Reproductive Health Unit; SES: Socio Economic Status; SSA: Sub Saharan Africa
} 


\section{Acknowledgements}

This study was financially supported through a grant by the Norwegian Ministry of Foreign Affairs to the Government of Malawi under Programme Title MWI 12/0010 Effect Evaluation of Performance Based Financing in Health Sector. The Malawi College of Medicine as implementing institution is recipient of this grant. Technical assistance was made possible through support of the Translating Research into Action, TRAction, and is funded by United States Agency for International Development (USAID) under cooperative agreement number GHS-A-00-09-00015-00. The findings of this study are the sole responsibility of Heidelberg University, Germany, and College of Medicine, Malawi, and do not necessarily reflect the views of USAID or the United States Government. We are grateful to the Ministry of Health staff, all district health officers, and health facility management at the study sites for their active support of the work. We are also grateful to all the women who participated in the study and all the enumerators for their contribution to the research.

\section{Availability of data and materials}

Due to confidentiality agreements, we are not able to share our raw data.

\section{Authors' contributions}

CK conceptualized the paper, contributed to the design of data collection tools, collected data, analysed data and wrote the manuscript. JL, JM, SB contributed in the designing of data collection tools, data collection, data analysis, interpretation of the results and reviewed the drafts critically, edited and gave important input to the results and discussion. MS and ASM critically reviewed and contributed to the development of the manuscript. MDA critically reviewed and supported the analysis and contributed to the development of the manuscript from its early draft, edited and gave important input to the results and discussion. MDA, CK, ASM, and SB were in charge of the overall study design, including the definition of the sample and the data collection strategy. All authors read and approved the final manuscript.

\section{Authors' information}

CK a Senior Lecturer in Environmental Health at The Malawi-Polytechnic, University of Malawi, Blantyre. She holds a PhD in Public Health and a degree of Master of Public Health. $J \mathrm{~L}$ is currently a PhD candidate at Heidelberg University. She holds a Diploma (MSc eq.) in Psychology. JM is a Lecturer in Economics at Chancellor College, University of Malawi, Zomba. He holds a $\mathrm{PhD}$ in Public Health and a Master's degree in Health Economics. SB is a senior public health researcher and holds a doctoral degree in medicine (Dr. med.) and a Master's degree in International Public Health. MS is a Professor and Director of Research at James P. Grant School of Public Health, BRAC Institute of Global Health, BRAC University, Bangladesh. She holds a $\mathrm{PhD}$ in Public Health. ASM is a Professor in Epidemiology and Community Health at the University of Malawi College of medicine. He holds a PhD in Infectious Diseases and Epidemiology and is Board Certified in Public Health. MDA is Associate Professor at the Institute of Public Health at Heidelberg University. She holds a PhD in Public Health and a Master's Degree in International Health Care Management, Economics, and Policy.

\section{Competing interests}

The authors declare that they have no competing interests.

\section{Ethics approval and consent to participate}

The Ethical Commission of the Medical Faculty of Heidelberg University, Germany (protocol number S-256/2012) and the University of Malawi College of Medicine Research and Ethics Review Committee (COMREC) (protocol number P.02/13/1338) granted ethical clearance for the study. We also sought permission from District Health Officers (DHOs) and District Commissioners (DCs) of the respective districts before data collection. We obtained written consent from all study participants; fingerprints were accepted as signatures for women who could not read and/or write [37]. The anonymity of participants was protected by numerically coding both surveys and transcribed materials to keep responses confidential.

\section{Publisher's Note}

Springer Nature remains neutral with regard to jurisdictional claims in published maps and institutional affiliations.

\section{Author details}

Institute of Public Health, Faculty of Medicine, Heidelberg University, Im Neuenheimer Feld 324, D-69120 Heidelberg, Germany. ${ }^{2}$ School of Public Health and Family Medicine, College of Medicine, University of Malawi, Private Bag 360, Chichiri, Blantyre 3, Malawi. ${ }^{3}$ Environmental Health Department, The Malawi Polytechnic, University of Malawi, Private Bag 303, Chichiri, Blantyre 3, Malawi. ${ }^{4}$ James P. Grant School of Public Health, BRAC University, 66 Mohakhali, Dhaka 1212, Bangladesh.

Received: 30 May 2016 Accepted: 22 May 2017

Published online: 08 June 2017

\section{References}

1. Graham WJ, Varghese B. Quality, quality, quality: gaps in the continuum of care. Lancet. 2012;379:e5-6.

2. Kinfu Y, Poz D, Mario R, Mercer H, Evans DB. The health worker shortage in Africa: are enough physicians and nurses being trained? WHO. 2009;87:225-30.

3. Tetui M, Ekirapa EK, Bua J, Mutebi A, Tweheyo R, Waiswa P. Quality of Antenatal care services in eastern Uganda: implications for interventions. Pan Afr Med J. 2012;13:27

4. 4. Ganle JK, Fitzpatrick R, Otupiri E, Parker M. Addressing health system barriers to access to and use of skilled delivery services: perspectives from Ghana. Int J Health Plann Manag. 2016;31(4):235-53.

5. Atim C, Fleisher LK, Hatt L, Musau S, Arur A. Health Financing in Africa Today: Challenges and Opportunities. Washington, DC: Africa's Health in 2010, Academy for Educational Development, and Bethesda: Health Systems 20/20 Project, Abt Associates Inc.; 2008.

6. Toonen J, Canavan A, Vergeer P, Elovainio R. Learning Lessons on implementing Performance Based Financing, from a multi-country evaluation 2009. http://www.who.int/contracting/PBF.pdf. Accessed 10 Mar 2016.

7. Fritsche GB, Soeters R, Meessen B. Performance-Based Financing Toolkit. Washington, D.C.: World Bank; 2014.

8. Eijkenaar F, Emmert M, Scheppach M, Schöffski O. Effects of Pay for Performance in Health Care. A Systematic Review of Systematic Reviews. Health Policy. 2013;110:115-30.

9. Gorter A, Ir P, Meessen B. Evidence Review. Results-Based Financing of Maternal and Newborn Health Care in Low- and Middle-Income Countries. Study commissioned and funded by the German Federal Ministry for Economic Cooperation and Development (BMZ) through the sector project PROFILE at GIZ - Deutsche Gesellschaft für Internationale Zusammenarbeit; 2013.

10. Soeters R, Peerenboom PB, Mushagalusa P, Kimanuka C. Performance-Based Financing Experiment Improved Health Care In The Democratic Republic Of Congo. Health Aff (Millwood). 2011;30:1518-27.

11. Soeters $R$, Vroeg P. Why there is so much enthusiasm for performancebased financing, particularly in developing countries. Bull World Health Organ. 2011;89:700.

12. Savedoff WD. Basic Economics of Results-Based Financing in Health. Bath: Social Insight; 2010

13. Basinga P, Gertler PJ, Binagwaho A, Soucat ALB, Sturdy J, Vermeersch CMJ Effect on Maternal and Child Health Services in Rwanda of Payment to Primary Health-Care Providers for Performance. An Impact Evaluation. Lancet. 2011;377:1421-8.

14. Kinoti S. Effects of Performance Based Financing on Maternal Care in Developing Countries. Access, Utilization, Coverage, and Health Impact. USAID-TRAction Project; 2011.

15. Meessen B, Kashala JP, Musango L. Output-based payment to boost staff productivity in public health centres: contracting in Kabutare District, Rwanda. Bull World Health Organ. 2007;85:108-15.

16. Peabody J, Shimkhada R, Quimbo S, Florentino J, Bacate M, McCulloch CE, et al. Financial Incentives And Measurement Improved Physicians' Quality Of Care In The Philippines. Health Aff (Millwood). 2011;30:773-81.

17. Witter S, Toonen J, Meessen B, Kagubare J, Fritsche G, Vaughan K. Performance-based financing as a health system reform: mapping the key dimensions for monitoring and evaluation. BMC Health Serv Res. 2013;13:367.

18. 18. Witter S, Fretheim A, Kessy FL, Lindahl AK. Paying for Performance to Improve the Delivery of Health Interventions in Low- and Middle-Income Countries. Cochrane Database Syst Rev. 2009, Issue 3. Art. No.:CD007899.

19. Lim SS, Dandona L, Hoisington JA, James SL, Hogan MC, Gakidou E. India's Janani Suraksha Yojana, a Conditional Cash Transfer Programme to Increase Births in Health Facilities. An Impact Evaluation. Lancet. 2010;375:2009-23. 
20. Bonfrer I, Van de Poel E, Van Doorslaer E. The effects of performance incentives on the utilization and quality of maternal and child care in Burundi. Soc Sci Med. 2014;123:96-104.

21. Eichler R, Auxila P, Pollock J. Performance-Based Payment to Improve the Impact of Health Services: Evidence from Haiti. 2001.

22. Bonfrer I, Soeters R, van de Poel E, Basenya O, Longin G, van de Looij F, et al. Introduction Of Performance-Based Financing In Burundi Was Associated With Improvements In Care And Quality. Health Aff (Millwood). 2014;33: 2179-87.

23. Huntington D, Zaky HHM, Shawky S, Fattah FA, El-Hadary E. Impact of a Service Provider Incentive Payment Scheme on Quality of Reproductive and Child-health Services in Egypt. J Health Popul Nutr. 2010;28:273-80.

24. Eichler R, Islam M, Beith A. Performance Based Incentives: Primer for USAID Missions. 2010. http://pdf.usaid.gov/pdf_docs/Pnadx747.pdf. Accessed 10 Mar 2016.

25. Das A, Gopalan SS, Chandramohan D. Effect of pay for performance to improve quality of maternal and child care in low- and middle-income countries: a systematic review. BMC Public Health. 2016:16:321.

26. Dagur, $V$, Senauer, K, Switlick-Prose K. Paying for Performance: The Janani Suraksha Yojana Program in India. Bethesda, MD: Health Systems 20/20, Abt Associates Inc. 2009.

27. van den Broek N, Graham W. Quality of care for maternal and newborn health: the neglected agenda. BJOG Int J Obstet Gynaecol. 2009;116:18-21.

28. Hulton LA, Matthews Z, Stones RW. A framework for assessing quality of maternal health services and preliminary findings from its application in Urban India 2005.

29. Wilde B, Starrin B, Larsson G, Larsson M. Quality of care from a patient perspective-a grounded theory study. Scand J Caring Sci. 1993;7:113-20.

30. National Statistical Office. Malawi Demographic Health Survey 2010. Zomba: National Statistical Office; 2011.

31. National Statistical Office. Malawi MDG Endline Survey 2014. Zomba: National Statistical Office; 2015.

32. World Bank. Population ranking | Data -Malawi 2015. http://data.worldbank. org/data-catalog/Population-ranking-table (accessed February 1, 2016).

33. Malata A. Gap Analysis for the National Health Research Agenda of Malawi: Research Priorities for the Themes of Reproductive Health. 2010.

34. Colbourn T, Lewycka S, Nambiar B, Anwar I, Phoya A, Mhango C. Maternal mortality in Malawi, 1977-2012. BMJ Open. 2013;3:e004150.

35. McCoy D, Ashwood-Smith H, Ratsma E, Going from bad to worse: Malawi's maternal mortality. An analysis of the clinical, health systems and underlying reasons, with recommendations for national and international stakeholders: commissioned by Task Force 4 of the UN Millenium Project, 2004. 2004. http://www.gega.org.za/download/bad_to_worse.pdf

36. Kambala C, Morse T, Masangwi S, Mitunda P. Barriers to maternal health service use in Chikhwawa, Southern Malawi. Malawi Med J. 2011:23:1-5.

37. Kumbani L, Bjune G, Chirwa E, Malata A, Odland JØ. Why some women fai to give birth at health facilities: a qualitative study of women's perceptions of perinatal care from rural Southern Malawi. Reprod Health. 2013;10:1-12.

38. Lewycka SO. Reducing maternal and neonatal deaths in rural Malawi: evaluating the impact of a community-based women's group intervention. Doctoral. UCL (University College London); 2011.

39. Brenner S, Muula AS, Robyn PJ, Bärnighausen T, Sarker M, Mathanga DP, et al. Design of an impact evaluation using a mixed methods model-an explanatory assessment of the effects of results-based financing mechanisms on maternal healthcare services in Malawi. BMC Health Serv Res. 2014;14:180.

40. RBF4MNH Options Office. Inception Report Results Based Financing for Maternal and Neonatal Health (RBF4MNH Initiative) 2012-2014. Lilongwe/ London: RBF4MNH Options Office; 2012.

41. Creswell JW, Plano Clark VL. Designing and conducting mixed methods research. 2nd ed. Thousand Oaks: SAGE Publications; 2011.

42. Creswell J. Research Design, Qualitative, Quantitative and Mixed Methods Approaches. 3rd ed. Thousand Oaks: Sage Publications; 2009.

43. Kambala C, Lohmann J, Mazalale J, Brenner S, De Allegri M, Muula AS, et al. How do Malawian women rate the quality of maternal and newborn care? Experiences and perceptions of women in the central and southern regions. BMC Pregnancy Childbirth. 2015;15:169.

44. Angrist JD, Pischke J-S. Mostly harmless econometrics: an empiricist's companion. Princeton: Princeton University Press; 2009.

45. Cameron AC, Gelbach JB, Miller DL. Bootstrap-Based Improvements for Inference with Clustered Errors. http://hdl.handle.net/10419/31404. 2008. http://www.mitpressjournals.org/doi/abs/10.1162/rest.90.3.414\#.Vq5jEuZReSo. Accessed 31 Jan 2016.
46. Cameron AC, Gelbach JB, Miller DL. Bootstrap-Based Improvements for Inference with Clustered Errors. National Bureau of Economic Research; 2007.

47. Cameron AC, Miller DL. A Practitioner's Guide to Cluster-Robust Inference. J Hum Resour. 2015:50:317-72.

48. Hsieh HF, Shannon SE. Three Approaches to Qualitative Content Analysis. Qual Health Res. 2005;15:1277-88.

49. Bradley EH, Curry LA, Devers KJ. Qualitative Data Analysis for Health Services Research. Developing Taxonomy, Themes, and Theory. Health Serv Res. 2007;42: $1758-72$.

50. Thurmond VA. The Point of Triangulation. J Nurs Scholarsh. 2001;33:253-8.

51. Smit J, van den Berg C, Bekker L-G, Seedat S, Stein D. Translation and crosscultural adaptation of a mental health battery in an African setting. Afr Health Sci. 2006;6:215-22.

52. McCarney R, Warner J, lliffe S, van Haselen R, Griffin M, Fisher P. The Hawthorne Effect: a randomised, controlled trial. BMC Med Res Methodol. 2007;7:30.

53. Record RJL, Kandoole PF, Asim S. Malawi economic monitor : adjusting in turbulent times. Washington: The World Bank; 2015.

54. Andaleeb SS. Service quality perceptions and patient satisfaction: a study of hospitals in a developing country. Soc Sci Med. 2001;52:1359-70.

55. Ebu NI, Owusu M, Gross J. Exploring women's satisfaction with intrapartum care at a teaching hospital in Ghana. Afr J Midwifery Womens Health. 2015;9(2):115-21.

56. Kiracho EE. Increasing access to quality health care for the poor: Community perceptions on quality care in Uganda. Patient Prefer Adherence. 2009;3:77-85.

57. Oladapo OT, Iyaniwura CA, Sule-Odu AO. Quality of antenatal services at the primary care level in southwest Nigeria. Afr J Reprod Health. 2008;12:71-92.

58. Rudman A, El-Khouri B, Waldenström U. Women's satisfaction with intrapartum care - a pattern approach. J Adv Nurs. 2007:59:474-87.

59. Srivastava A, Avan Bl, Rajbangshi P, Bhattacharyya S. Determinants of women's satisfaction with maternal health care: a review of literature from developing countries. BMC Pregnancy Childbirth. 2015;15:97.

60. Mannava P, Durrant K, Fisher J, Chersich M, Luchters S. Attitudes and behaviours of maternal health care providers in interactions with clients: a systematic review. Glob Health. 2015:11:36.

61. Kumbani LC, Chirwa E, Malata A, Odland JØ, Bjune G. Do Malawian women critically assess the quality of care? A qualitative study on women's perceptions of perinatal care at a district hospital in Malawi. Reprod Health. 2012;9:30

62. Lino Y, Sillabutra J, Chompikul J. Factors related to the perception of pregnant women regarding antenatal care in Nakonpathom province. Thailand. 2011:9:105-16.

63. WHO. WHO / Prevention and elimination of disrespect and abuse during childbirth. WHO; 2014. http://www.who.int/reproductivehealth/topics/ maternal_perinatal/statement-childbirth/en/. Accessed 31 Jan 2016.

64. Grøndahl VA. Patients' perceptions of actual care conditions and patient satisfaction with care quality in hospital. 2012.

65. Matizirofa L. Perceived Quality and Utilisation of Maternal Health Services in Peri-urban, Commercial Farming, and Rural Areas in South Africa. University of the Western Cape; 2006

66. Gausia K, Ryder D, Ali M, Fisher C, Moran A, Koblinsky M. Obstetric Complications and Psychological Well-being: Experiences of Bangladeshi Women during Pregnancy and Childbirth. J Health Popul Nutr. 2012;30:172-80.

67. Simkin P. Pain, Suffering, and Trauma in Labor and Prevention of Subsequent Posttraumatic Stress Disorder. J Perinat Educ. 2011;20:166-76.

68. Paul F. Health Worker Motivation and the Role of Performance Based Finance Systems in Africa, A Qualitative Study on Health Worker Motication and the Rwandan Performance Based Finance Initiative in District Hospitals. London: London School of Economics; 2009.

69. Bhatnagar A, George AS. Motivating health workers up to a limit: partial effects of performance-based financing on working environments in Nigeria. Health Policy Plan. 2016;czw002. 